Portland State University

PDXScholar

\title{
A test of the simple recessive hypothesis for the inability to taste phenyl-thio-urea: a family study
}

Susan I. Wolf

Portland State University

Follow this and additional works at: https://pdxscholar.library.pdx.edu/open_access_etds

Part of the Biological and Physical Anthropology Commons, and the Genetics Commons Let us know how access to this document benefits you.

\section{Recommended Citation}

Wolf, Susan I., "A test of the simple recessive hypothesis for the inability to taste phenyl-thio-urea: a family study" (1973). Dissertations and Theses. Paper 2145.

https://doi.org/10.15760/etd.2143

This Thesis is brought to you for free and open access. It has been accepted for inclusion in Dissertations and Theses by an authorized administrator of PDXScholar. Please contact us if we can make this document more accessible: pdxscholar@pdx.edu. 
A MEST OH TEE STMPLE RECBSSIVA FYPCTYESIS FOR MEE INABILITY

TO PASTE FEENYL-TEIOWUREA A FAMILY STUDY.

by

SUSAN I. VOLF.

$A$ thesis submitted fa partiel fulfillment of the roquirements for the degree of

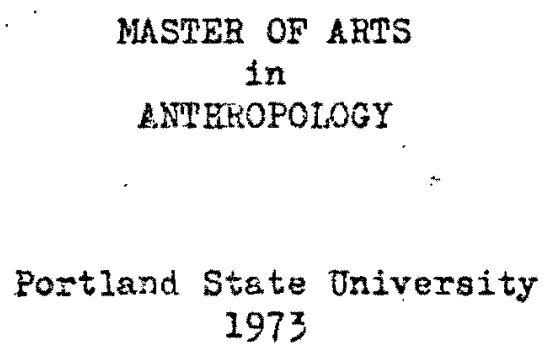


AN ABSTRACT OF THE THESIS OP Susan I. Wolf for the Mastex of Arts in Anthropology presented Auguat $20,1973$.

Title: A Test of the Simple Recessive Hypothesis for the Inability to Taste Phenyl-thio-urea: A Family Study.

APPROTED BY MEMBERS OF TEE THESIS COMIRTER:

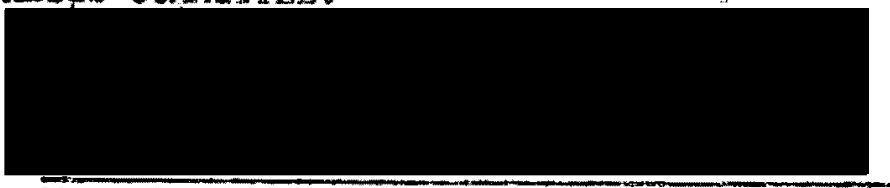

Marc R. Feldegman, Chairman

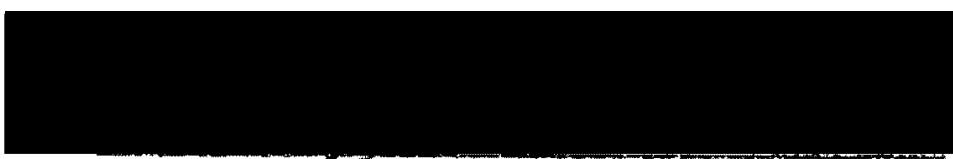

Daniel J. Screans

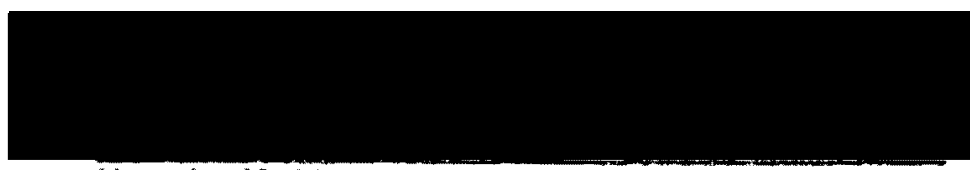

Morris Jeitman

This thesis is a report on the analysis of family data gathered to test the simple recessive hypothesis for the inabillty to taste pheryl-thto-urea (P.T.C.). The simple recessive hypothesis states that the inability of a minority of persons to taste high concentrations of P.T.C. is due to the action of an autosomal recessive gene In the homozygous condition.

The dats consisted of the taste thresholds for P.T.C. of 35 families, incluaing parents and their chilören. the taste thresholds were determined by the well known Harris and Kalnus method which 
employs a series of fourteen dilutions of Y.T.C. in distilled water in which each solution is half as strong as the previous one. Ihe threehold solution concentration at which eech subject could taste was preciseiy determined by a sorting test in which the subject was required to separate by taste cups containing P.T.C. solution from cups contalning distilled watex.

Some previous experiments on the inheritance of the F.T.C. taste character have reported results which departed significantly from the predictions of the simple recessive hypothesis when taste thresholds were deternined by the Harris and Kalmus technique. Some of these divergences may have been due to measurement error caused by deterioration of the P.T.C. solutions over time. In the present study precautions were taken to mix, atore, and administer the solutions under carefuliy controlled conditions, so as to minimize the possi-. bility of errors in the threshold determination.

The resulting taste threshold data were analyzed by two different methods to deternine if they. agreed with the predictions of . the simple recessive hypothesis. The firet was Fisher's method which uses gene frequencies estimated from the parental sample and Mendelian retios to predict the number of families which (a) contain 11 taster children and (b) contein at least, one non-taster child for both taster $x$ taster and taster $x$ non-taster matings. The second, was Suith's recessives estimation method which utilizes no gene frequencies. Smith's test uses Mendelian ratios to predict the exact number of non-taster chlldren in sibships containing at least one nontaster child for both taster $x$ taster and taster $x$ non-taster matings. 
Analysis of the 35 families by both nethods showed that the data clearly agreed with the simple recessive hypothesis. The data were also examined to determine if the age and sex of the subjects affected the taste threshold for P.T.C. No such effects were found.

The conclusions were drawn that (1) the precautions taken in the preparation, starage, and administretion of the solutions reduced measurement error and (2) the family data atrongly supported the aimple recessive hypothesis for non-tasting. Future research designs ahould concem include both a larger sample of families and careful care of solutions. 
TO THE OFFICE OF GRADUATE STUDIES:

The nembers of the Commttoe epprove the thesis of Susen I, Wolf preserted August 20, 1973.

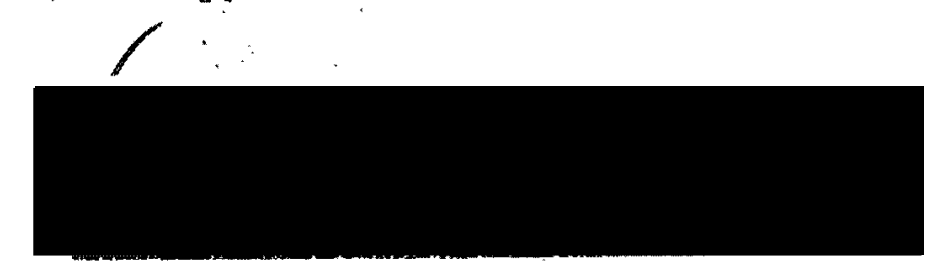

Maro R. Feloesman, Chaj rain

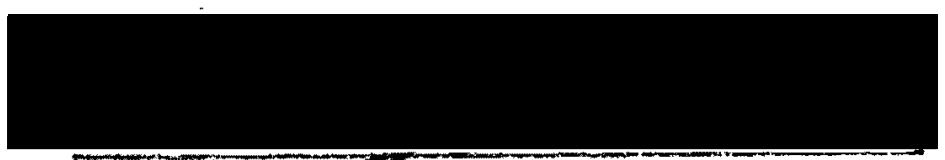

Daniel I: Scherins

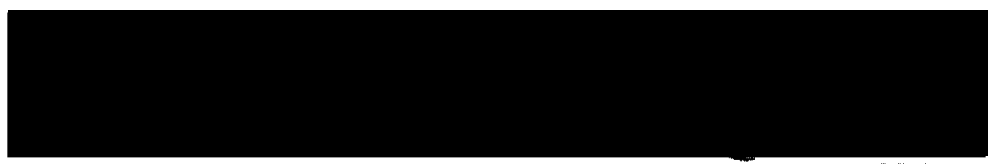

Morris Weithtra

APPROVED:

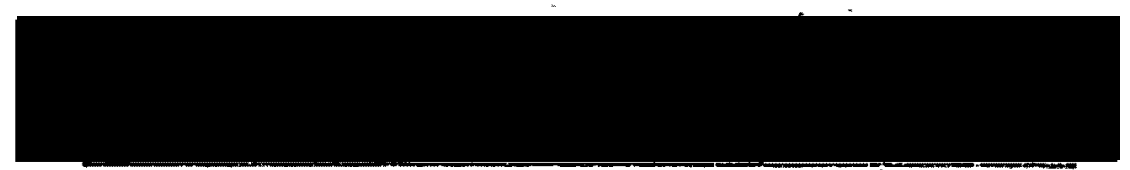

Thomas Newman, Head, Department of Anthropology

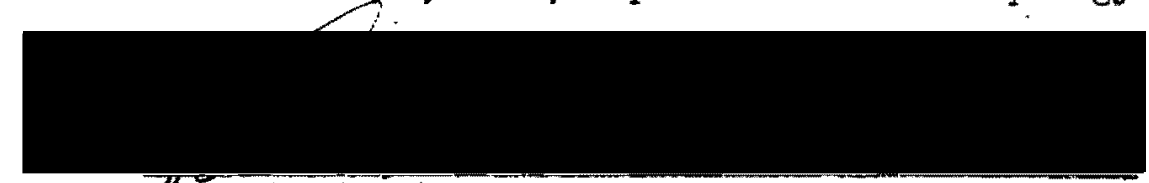

David T. Clarix, Dean of Graduate Studies

August 20,1973 
LIST OF TABLES. ................... v

LIST OF FIGURES ......................... vi

CEAPTER

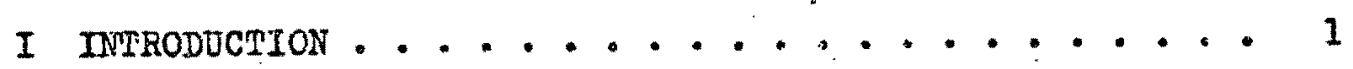

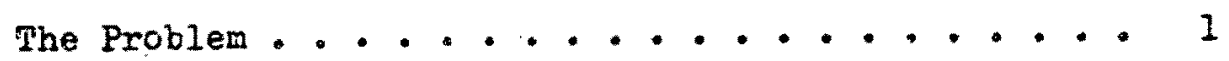

Historical Bsckground ............ 2

Crystal Studies

Solution Studies

Current Status of the Problem .......... 10

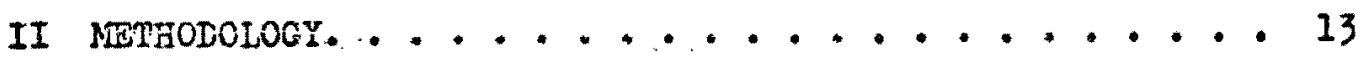

The sample. . . . . . . . . . . 13

Size and Composition of the Sample

Selection of the Sample Families

Randomness of the Matings

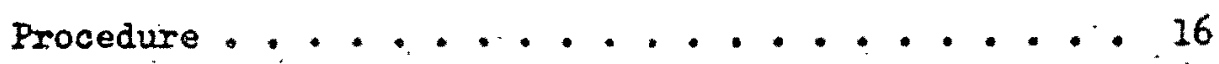

The Test Situation

The Test Solution

Testing the Threshold.

Possible Misrepresentation of Taste Sensations

The Color Code

Changing Cups

Summary of Testing Techniques

Analysis of Data. . . . . . . . . . 25

Operational Definitions of Taster and Non-Tastex:

A Method of Analysis Not Used in the Present Paper

Two Methods of Ansiysis Usea in the Present Paper 
III RESULTS. . . . . . . . . . . . . . . . . 31

Basio Data. .. . . . . . . . . . . . 31

The Tagte Threshold Diatribution

Comparison of the Taste Phreshold Distribution by Age and Sex

Estimation of the Gene Frequencies

Phenotypic Constitution of the 35 Families

Analyzes. . . . . . . . . . . . . 35

Randomness of the Matings

Fisher's Method of Analysis

Smith's Recessives Estimation Method

IV DISCUSSION, SUMARY, AND CONCLUSIONS . . . . . . . 44

Comparison of the Present Study with Sib-Pair

and Other Family Studies. . . . . . . . . 44

Sib-Pair Studies

Effectg of Misclassificstion

Fanily Studies

Methodological and Theoretical Problems... . . 51

The Antimode as the Dividing Line Between

Taster and Non-tasters

The Irsue of Incomplete Dominance

Possible Sources of Ontogenetic Variation in the

Expression of the Taste Character........ 55

The Influence of Age

The Influence of Sex

The Influence of Smoking

Sumary of Data on Ontogenetic Variation

Summary of the kesults of the Present Study .... . 63

conclusion................. 64 


\section{LIST OF TABTES}

\section{TABLE}

PRGE

I Test for the Randomness of the lutings . . . . . . 16

II Test of Independence for the kroportions of Male

and Femalo Testers and Non-Tasters Among the

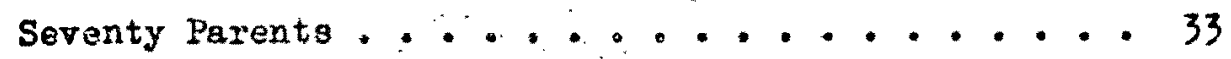

III Two-way Analysis of Variance: Male/Female and

Adult/Child P.T.C. Taste Thresholds ........ 34

IV Summary of the Phenotypic Composition of the

Thirty-five Families with 106 Children. . . . . 36

$v$ Summary of the Anelyeis of the $\bar{T} \times \bar{t}$ Fanilies. . . . 39

. VI Sumary of the Analysis of the $\overline{\mathrm{T}} \times \overline{\mathrm{T}}$ Families. . . . 39

VII Summary of Analysis by Fisher's Method . . . . . . 40

VIII Smith's Variation of Flsker's Method: Sumary . . . 40

IX Obeerved and Expected Numbers of Non-Taster.

Children in $\bar{T} \times \bar{T}$ Families with at Least

One Non-Tester Child. $\therefore . . . . . . . . .42$

$X$ Observed and Expected Numbers of Non-Taster.

Children in $\overline{\mathrm{T}} \times \overline{\mathrm{t}}$ Families with at Least

One Non-Taster Child. . . . . . . . . . 4 43 


\section{LIST OF FIGJFES}

FIGURE

PAGE

1 Taste Threshold Distribution: of the Entire Sample. . . 32 


\section{CHAPTER. I}

\section{INTRODUCTION}

\section{THE FFOBLEM}

In the study of human genetics, the precise mode of inheritance of many traits defies elucidation because available methods of obserration and measurement cennot record the action of genes themselves. Inferences ebout the genotype of the individual must be made on the basis of observable phenotypic traits or trait complexes which may be far removed fron the site of sene action." Considerable modification of a genetic trait may be introduced by epistasis and pleiotropy as wel 1 as by the influence of the environment.' These complex interactions may produce phenotypes which do not accurately reflect the genotype. Single gene polymorphisms constitute an exception to this rule. Such systems are simple enough to be compared with expectations derived from the laws of classical Mendelian genetica. In man, the best known polymorphismo are the blood groups which are controlled by genes obeying mendel's laws very. precieely. :

Since the early 1930 's the ability or inability to taste the cherical substance phenyl-thio-urea (P.T.C. $)^{1}$. has been considered another single gene polymorphism. During that time it was generally held that the ingbility of a minority of persons to taste high concentrations of P.T.C. was due to the ection of an autosomal recessive 
gene in the homozygous form.: However, in the 1950's, with the introduction of more refined techniques of testirg, this "simple recessive hypothesis" became euspect as an explenation for the inheritance of the trait (Harris and Kalmus, 1951; Das, 1956; Das, 1958).

\section{HISTORICAL BACKGROUND}

\section{Crystel Studies}

In 1931 Dr. A. L. Fox of the DuPont Labosatories discovered that a few crystals of the P.T.C. placed on the back of the tongue produced two very different reactions. (1) most persons reported that the substance had a very strong bitter "taste, and (2) a minority cculd percelve no flavor at all (Fox, 1931). From this he concluded that the ability to taste the substance could segregate persons refrardeas of ege, sex, or race into classes--"tasters" and "non-tasters". He also established that not only F.T.C. but other compounds containing the specific chemical linkaget

$$
\begin{array}{r}
=\mathrm{N}-\mathrm{C}- \\
\mathrm{N}
\end{array}
$$

in the molecule could in most cases produce a similar discrimination between "tasters" and "non-tasters" and that the classifications made by all these related compounds were generally congruent. Further research by Harris and Kalmus (1949a), Barnicot, Harris and Kalmus (1951), and others confirmed and amplified the original observation through the study of additional compounds including para-ethoxyphenyl-thio-carbamide, thio carbanilide, thiouracil, and others. 
The discovery of the taste polymorphism prompted geneticists to attempt to deternine whether "tasting" and "non-tasting" were under genetic control. Snyder (1932) westea 800 samilies, Including parents and their children, using the dry crystal nethod described by Fox. On the basis of three crlteria, Snyder concluded that "non-tasting" of P.T.C. was inherited as an sutosomal recessive trait controlled by a single peir of alleles. He based his conclusion on the following observations, (1) sex linkage was ruled out because no significant difference in the number of male and femele ron-tasters was found; (2) when neither parent could taste the substance, virtually none of the children tasted. Exceptione to this rule constituted less than one percent of those tested and might well have been due to 111 egitimacies, gooptions, or errors in reporting or recording the data.

A formal mathenatical analysis showed that the number of non-taster children produced from each of the three possible types of matings-taster $x$ taster, taster $x$ non-taster, and non-taster $x$ non-tasterclosely conformed to the number expected for a trait whose inheritance obeys Mendelian laws.

\section{Solution Studies}

Early Work. In 1932 Blakeslee introduced simple solution method of testing to determine if the taste polymorphism still appeared when the chemical was pleced in solution. He used a series of four dilutions of P.T.C. In water where each solution wes four times stronger than the previous one. In the strongest solution the proportion of P.T.C. to water was 1:5,000; the weakest contaired $1: 320,000$. 
Blakeslee operationally defined non-testers as persons who could not taste the strongest of his four dilutions $(2,5,000)$.

The dilution technique showed P.T.C. tegte acuity to be a continuously variable trait rather than a diserote poiymorphism--a fect which testing with crystals had masked. When the distribuition of taste thresholds wos plotted a division eppeared between individuals ciassified as non-tasters and those with a threshold at $1: 5,000$ alear "tasters". This was the first observation of a bimodal curve of taste threshoids for P.T.C.

Blakeslee used his solution technique to perform a family study. The date obtained from 103 femilies lent further support to the eimple recessive hypothesis. Blakeslee observed that smong the taster offspring from taster $x$ non-taster matings, acuity for P.P.C. increased with the sensitivity of the taster parent. The matings of non-tasters with strong tasters tended to yield strong taster children. When both parents were tasters the effect of the parental thresholds on the children was unclear. Blakeslee did not perform a formal mathes matical analysis of his data, but they clearly showed that a mating between two non-tasters (subjects unable to taste the 185,000 solution) yielded only non-taster children. 'this result strongly supported Snyder's work.

Comparizon of Crystal and Solution Results. The introduction of the solution technique immediately raised the question whether the . clessifications produced by the crystal and solution methods of testing vere congruent. Crystal tests could produce only two gross clasBifications--tasters and non-tagters-which aeemed to have fairly 
alear genet1c implicatione. Solution teste on the other hand, could yield eny number of classes simply by yerying the number and size of the dilution steps in the series. Researchers wondered if the taste threshola distribution given by the diution technique would show a distinction between tasters and non-tasters from which genetic conclusions concordant with those producea by crystal tests could be drawn. Blakeslee's work had alreacy shown that the distribution of taste thresholds in his dilution stady followed a bimodal curve. One mode contained the operationally defined non-tasters, and the other contained the tasters. This result raised the question of where the thresholds of non-tasters (defined by the crystal method) would fell if they were tested by the dilution method. Would they occur in the "non-taster" region of the curve or would they be normally distributed over the entire range of possible thresholds?

In 1936, Setterfield, Schott, and Snyder devised an experiment to attempt to solve the problem. They tested 584 individuals for both dilution thresholds and reactions to crystals. The solution testing was very extensive; 50 solutions ranging in strength from $.00001 \%$ P.T.C. to $1.0 \%$ were used. The results showed the following patterns: (1) tabulation of the data showed a definite bimodality of threshold groupings, (2) one of the modes appeared among the tasters of crystals and the other among the non-tasters of crystals, (3) there was no absolute break between the taste threshold distributions of the tasters of crystals and the non-tasters of crystals, and (4) tasters of crystals showed a gignificantly higher mean taste acuity when they were tested for threshold than did the non-tasters of 
crystals. Mhese resulta showed that tasters of crystals had a higher acuity for P.T.C. in solution than do non-tagters of crystals and that testing by solutions containing different concentrations of P.P.C. produced classifications which were generally congruent with those produced by crystal testing. The congruence of the classification indicated that genetic analyses of deta gathered, by either method should give generally similar results, es Blakeslee's initial family study using a dilution technique hed suggested.:

The simple threshold method represented an improvement over the crystal method in that it emphesized the variability of the taste character; however, the use of dilutions had the disadvantage of being highly subjective. The experimenter had to rely totally on the report of his subject, and for various reasons this report might rot be accurate. The subject could becone confused or fatigued or respond to intentional on unintentional psychological suggestions by the experimenter. In some cases the subject might even misrepresent his response. Early dilution studies hed to depend on repeated testing of the same subjects for reliable results; no technique existed to deternine objectively whether a subject" could really taste a given solution at a given time.

Later Solution Studies: The Harris and KaImus Technique. Harris and Kalmus (1949b) introduced two new techniques which greatly helped to stendardize the results schieved by olution testing. One of the innovstions was a solution scale containing fourteen serial dilutions of P.T.C. in water. The first solution contained 1.3 grams P.T.C. in one liter of water. The second solution was made by dilut- 
ing one liter of the firet solution with one liter of water. The process of dilution by half ith water continued through solution No. 14. The subject tasted a small emount of each of the solution in turn beginning with Wo. 14. When the subject resched a point at which he declared that the solution had a definite taste, he was required to perform 2 sorting test in which the subject was presented with eight cups. Four of the cups contained the threshold solution at which the subject had declared a teste, and four others contained water. The subject then tasted the solution from each cup in turn and separated those cups containing P.T.C. from those containing water. Success or falluxe in the sorting test provided a simple, corrobative means of determining whether the subject could actually discriminate between the threshold solution and water. The introduction of a atandard solution scele with a reasonably emall number of steps together with the simple scrting test eliminated many of the errors inherent in olajer methods.

All of the reported data generated by the Harris and Kalmus . technique have fallen into a definite pattern. The distribution of taste thresholds is bimodal with the amaller mode representing the non-tasters and the larger representing the tasters. The class which constitutes the low point between the two modal categories is generally termed the "antimode". This class generally contains very few persons and is usually taken as the dividing line between the taster and non-taster phenotypes (Harris and Kalmus, 1949b; Harris and Kalmus, 1951, Pons, 1955). This use of the antinode presents certain methodological problems in the interpretation of the data. In oome caser, 
the antimode may contain two classes (Pons, 1960). Another problem is the classification of the eritimode itself as either a part of the tasters or the non-tusters. Since a total separation between the modes rarely exists, the investigator must decide in each case which phenotypic grouping will contain the antimode. ihis overlap of the two distributions indicates that while the classifications ftt well enougi sor definite testers and non-iasters some misclasaification of the intermediate types is inevitebie (Kalmus, 1958).

Confusion also existi as to how wuch information about the genotype may be gleaned from the taste threahold. Most investigators regerd tasting as a fully dominant trait with no distinction posaible between heterozygous and homozygous testers. Certain data, however, Indicete thet heterozyous tasters may have a lower mean throbhold than homozygous tasters. Das (1958) in a study of 126 families in India found that the mean threshold of taster children from taster $x$ non-taster families was 0.561 dilution steps lower than the mean for taster children from taster $x$ taster matings. This difference was. statistically significant and supported the hypothesis that the taster gene may be incompletely dominart. If non-tasting is a recessive trait, tastex chllaren from taster $x$ nontaster matings must be heterozygous while taster children from taster $x$ taster matings will be a mixture of heterozygotes and honozygotes. The higher mean threshold in the fixed Group could result from 2 higher acuity of taste of homozygotes. If this is the case, some discrimination of heterozygous and homozygous tasters may be poselble on the basis of threshola testa. 
Sib-Pair and Pamily Stuaies." The introcuction of the sorting technique has led to a re-evaluation of the simple recesaive hypothesio for P.F.C. Don-tasting. Harris and Kalmus (1951), Das (1956), and Pons (1960) have studied the problera of inheritance on the basis of taste threshold distributions of 384,845 , and 177 sib-pairs reapectiveiy. In each-study two hypotheses were tested. The first was the simple recessive hypotiesis based on estimates of gene frequencles. The second was called the chance hypothesis. The chance hypothesis holds that the phenotypic constitution of the sib-pairs is independent of any genetic influence; it is totally dependent on the chance alstribution of the non-tasting phenotype in the sample. Harris and Kelmus found to their surprise that thetr date diverged significantly from the predictions of both hypotheses but actualiy fell closer to the chance sypothesis. Das also found that his data diverged signiflcantly from the predictions of both hypotheses, but in his case they fell closer to the simple recessive hypothesis. Pons, on the other hand, found that his dats on 177 sib-pairs conformed closely with the predictions of the simpie recessive hypothesis.

A study by Das (1958) in which 126 families, including parents and their children, were tested cast furthex doubt on the simple recessive hypothesis. Although some of his data agreed with the predictions of the hypothesia, there were many discrepancies in detail. As has been previoualy discussed (p. 8), some evidence indicated that the taster gene may be incompletely dominant. Das also advanced the theory that the taster gene might be incompletely penetrant, but the 
nature of the influences which could inhibit penetrance were not discussed.

A second study containing entire families was performed in Norway (Kerton, 1958) and confirmed the simple recessive hypothesis. However, the work contains certain methodological peculierities which make its Interpretation difficult. Discussion of this study will be reserved therefore; until Chapter IV.

\section{CURRENT STATUS OF THE PROBLEM}

The inconclusive nature of the data on the inheritance of P.T.C. non-tasting clearly indicates a need for further study of the problem. The inconsistent results reported in aib-pair and family studies all carried out using the Karrie and Kalmus solutions and sorting test as well as similar nodes of mathematical analysis suggest that some of the discrepancies may result from measurement error. Possible sources of measurement error have not been discussed In the literature to any great degree, but they certainly deserve'. careful consideration. Since P.P.C. is an organic compound it is subject to deterioration from the action of light, air, and microorganisms particularly if it is in weak dilutions. Misclassification of the threshold could easily result if the test solutions had weakened. Some of the deviation found in many studies may be a direct result of such errors. Therefore this atudy hes a dual purpose. Firat, it provides another taet of the hypothesis that non-tasting of P.T.C. Is inherited as an autcoomal recessive trait controlled by a single paix of alleles. The data used for the test are the taste 
threshold diatributions of families which have been determined by the Harria and Kalmis method. The second objective jo to determine if stringent precautions in the preparation, storage, and use of the solutions car reduce problems of classification and result in a clearer antinode. 


\section{FOOTHOTES}

'Literature on the taster polymorphisin freely interchenges the terms phenlythiourea, phenylthiocarbamide, P.T.C. and P.M.J. FhenIythiocarbamide and phenydtiourea are equivalent. The Merck Index (1965: 820) 1ists phenylthiourea as the proper name of the substance and phenylthiocarbanide as its synonym. Whe chemical fomula is C6E5FHCSiH2 and the molecular weight io 152.22. The initials F.T.C. are the most common way of referring to the substance and this symbol will be used consistently throughout this paper to denote phenylthiourea. 


\section{HETHODOIOGY}

\section{TEE SAMPLE}

\section{Size and Composition of the Sample}

The sample consisted of thirty-five fomilies living in the Portland metropolitan area. Any conclusions drawn from this study would rest on a firmer besis if a larger semple could have been obtained. Data collection, however, had to be confined to a period of six weeks. Since whole families participated in the study, I found that evenings were the only time all family members were at home. To test a family of five ofiten took as long-as-an hour and a haif, depending on the amount of time spent in discussion of the experiment. This meant that I could normally test only one family per evening. These restrictions meant that thirty-five families was the maximum number I could accomodate.

Every effort was made to weight the sample toward families containing three or more children because a shortage of large families was identified as a common flaw in previous studies of P.T.C. tasting (Das, 1958: 201). Larger sibships are preferable for this kind of study because inferences with regard to the genotypes of the parents are based largely on the phenotypes of their chiloiren. Larger numbers of children give more opportunity to predict the parental genotypes. Onfortunately the short time aliowed for data collection forced ne to include more two child famllies than was originally 
intended. This reduced the average sibship size in the present study to $3.0 \mathrm{ch} 1 \mathrm{~d}$ ren.

\section{Selection of the Sample Families}

I used no specific technique for the selection of the sample families. Any available and willing family was included if it met the following criteria: (I) that both biological parents of the children were available for testing and (2) that the family contained et least two and preferably three or more children old enough to participate. Six years of age constituted the lower limit. I violated the second criterion onse; one family shows a single child. In this case, two children agreed to testing, but the second child left the local area before the tests could be completed.

\section{Randomess of the Matings}

Before any formal genetic analyses may be performed on family data, the randomness of the matings included in the parentel sample must be assessed. Mendelian genetics depends on the determination. of resemblences between parents and their offapring in single families. In human genetics, families are usually tco small and generation time too long for these predictions to be tested in aingle families. Population genetics handles this problem by dealing with the statistical consequences of Mendel's laws in a group of families, usually referred to a a population. Using mathematical formulations developed in population genetics, it is possible to predict the distribution of genotypes and phenotypes in a population. However, it is essential that the condition of random mating be fulfilled. Random 
mating means that the frequency of any particular type of mating is dictated by chance. (Non-random mating, i.e., inbreeding or positive assortative mating would lead to a shortage of heterozygotes and a surplus of homozygotes without changing the gene frequencies.)

In the present study, it is assumed that the entire population of the Portland metropolitan area metes at randon insofar as the ability to taste P.T.C. is concerned. In other words, people do not choose mates on the basis of their status as tasters or non-tasters. It must be determined if the frequencies of the four different phenotypic mating combinations found in the present sample conform to the frequencies predicted by random mating. For this reason, the four phenotypically possible matings have been placed in a $2 \times 2$ contingency table to determine if the condition of random mating applied. The mating types included the following possibilities: (1) both father and mother tasted; (2) father tasted and mother did not; (3) mother tasted and father did not; and (4) neither father nor mother tasted. The results are given below. The expected frequencies were computed in the usual manner using Yate's correction. 
TABLE I

TEST FOR TEE RANDOMNESS OF THE MATINGS

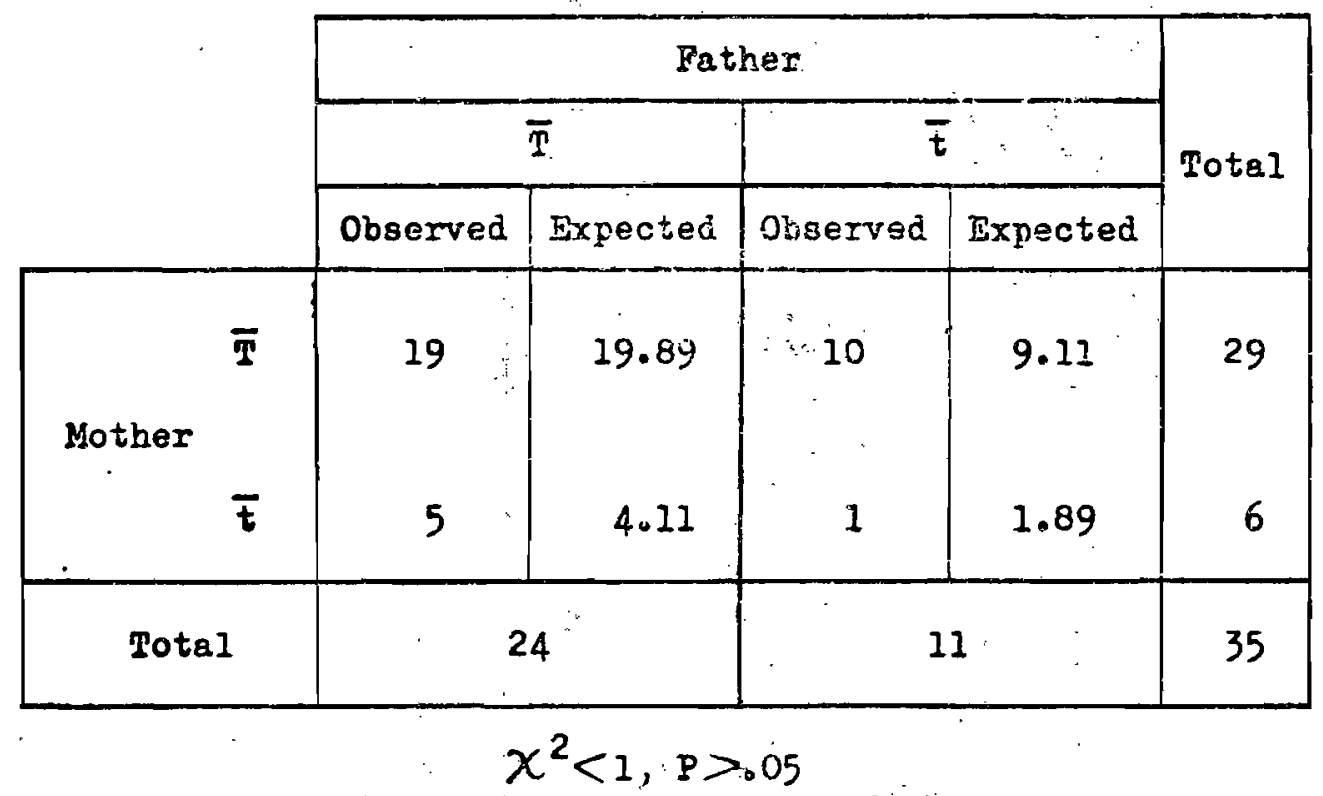

II. PROCEDURE

The Test Situation

Testing in the Hone. All taste testing was conducted in the homes of the subjects. Better experimentel control could have been. maintained if each member of the family had been tested separately and asked not to reveal the results to the others. This approach might have been reduced the influence of auggestions on family members later tested. However, many factora in the home setting made it impractical to isolate the subject during testing. Family nembers wishing to watch the tests were asked to remein quiet and they generally co-operated. Allowing the family to be present during the test had the advantage of reducing their anxieties about the procedure. The statistical anslysis of the data gathered in the home did not show 
that there were any undue influences upon tho test subjects by the circumatances described abcie. I concluded that there was no important social-psychological irpact on the taster/non-taster differentlation from group teating when the experimenter retained auficient control of the situation.

Tiae of Day. Freire-Maia (1960) found that the taste threshold of a single individual varied during the day and night. His preliminary work indicates, however, that the variation followed no defInite pattern. For example, taste ecuity does not rise steadily during the day and fall during the night. The exact effect of the time of testing is uncertain. For this reason, nearly all tests were conducted in the evening after the family had eaten dinner. ${ }^{1}$ only four of the thirty-five familiea couid not be tested at that time. of these four, three were tested in the aftemoon and the fourth in the morning. None of these four families presented any detectable anomalies that could be attributed to being tested at a different time of day.

The Test Solution

Preparation. The Harris and Kalmus method was used in preparing and administering the test solutions (Hazris and Kalmus, 1949b; Weiner and Lourie, 1969:117). The test chemical was 1-Pheny1-2thiourea. A series of P.T.C. solutions was prepared from a stock solution No. 1 containing 0.65 of P.T.C. dLssolved in $500 \mathrm{ml}$ hot distilled water. The water was meagured at room temperature and then brought to boiling over a bunsen burner. When the water reached the 
boiling point, the F.T.C. wes added and the solution stirred until the chemicel dissolved. The solution was then removed from the heat and allowed to cool until it could be handled easily. It was then filtered, decanted, and atored under refrigeration in an amber glass bottle to prevent deterioration. By diluting the $250 \mathrm{ml}$ of No. 1 at room temperature with 250 mi room temperature distilled water, solution No. 2 was obtrined, and so on through síccessive dilutions producing solutions No. $j$ through 14. It should be noted that the quantities given here ere exactly half of those given by Harris and Keimug because it was impractical with the laboratory facilities available to maxe a full liter of each of the fourteen solutions. Storege. The test solutions were stored in 4 oz. amber glass bottles with plastic caps. The 4 oz. bottles made an excellent field test kit because they were small, light, and easy to carry. The small bottle size necessitated refilling the bottles about once a week, but this was not a disadventage. P.T.C. is an organic compound which can be decomposed by light, air, and bacterial action, particularly in. weak dilutions (Lutz, personal communication). Each time the bottles ran low, I used stock No. I in the menner described above, to make enough of the weaker dilutions to fill all bottles to the top. Thts procedure constantly replenished the weaker solutions.

I prepared a fresh stock of solution No. I once. The solutions may begin to deteriorate after about thirty days. After one month of experimentation, I discarded all the original solutions and made fresh ones from new stock No. 1. To determine whether the new solutions were comparable to the origlnal, I re-tested several persons 
baving thresholds of 1,6, and 11 with the fresh dilutions. Ihe results were concordant with those obtained with the original solutions.

\section{Testing the Whreshold}

Temperature of the Solutions. Both the test solutions and aistilled water were kept under refrigeration. when not in use. Approximately three hours before a testing session, I removed the solutions and water from the refrigerator and allowed them to warm to room temperature. All test materials must be near the same temperature before use. If one is colder than the other, the subject may show a misleadingly high threshold because he was able to distinguish water from P.T.C. solutions by noting temperature differences rather than taste differences (Weiner and Lourie, 1969: 118). For similar reasons, tap water introduced into the test can skew the results. Many subjects found distilled water unplessantly flat and asked to use tap water for a control solution in the scrting test. Tap water differs greatIy from distilled water in temperature, taste, and mineral content. These differences may lead to threshold numbers far too high because the subject can easily distinguish the flavor of tap water from that of a weak.P.T.C. solution which tastes like distilled water to a nontaster. Therefore, tap water was never used.

The Dropper Test. I began each testing session by giving the subject a cup of distilled water to taste so that he would be familiar vith its flavor.

4 preliminary idea of the tagte threshold was given by having each subject taste about $3 \mathrm{ml}$ of No. 9 from a dropper. He wes told 
to awish the solution around in his mouth for a few seconds, (the taste generally appears after about five seconds on the back of the tongue) and to describe the flevor. If he answered "bitter" or that he could definitely taste the solution, I assumed that he was a taster. He then took a drink of distilled water to rinse his mouth and tasted about 3 ml of solution No. 10 in the same manner. This process continued until the subject declared that the sample was "tasteless" or that it tasted like distilled water. The subject then performed the 8 -tumbler sorting test (described below) on the weakest solution at which he could perceive a definite taste.

If the subject said that the original sample of No. 9 was tasteless, he took a drink of distilled water and tasted $3 \mathrm{ml}$ of Nos. $7,5, \ldots$ and so on until a level was reached at which he atated he could perceive a definite taste sensation. When this occurred, the subject performed the 8-tumbler test at the next weaker solution. For exemple, if the subject stated that solution No. 5 was bitter, he started the sorting test at No. 6. Skipping two steps when moving . from a weaker to a stronger dilution in the dropper test saved time, especially if the subject had a very low sensitivity for P.T.C. Starting the dropper test at solution No. 9 had certain advantages over starting at either No. 1 or No. 14 . If the test started at No. 14 and the subject was a low sensitivity taster, he sometimes imagined that very weak solutions had a flavor. This led to much time being wasted on unsuccessful sorting tests. If the test started at No. 1 , and the subject was a high sensitivity taster, he might refuse to continue the test because strong concentrations of P.T.C. are 
very unpieasant to many testers. Also strong solutions leave a definite aftertaste which may confuse the subject in later sorting tests. Solution No. 9 made a good starting point because many people have threshoids tinat fall there. This meant that such persons had to perform no more than one or two sorting tests to determine their thresholda.

The 8-Tumbler pest. After determining roughly the solution level at which the subject can taste, the 8-tumbler test was used to determine the threshold precisely. Eight five ounce Dixie cups patterned in four colors made excellent tumblers. These had to be marked in some way not noticeable to the subject. I employed a color code, explained later, to distinguish which cups held distilled water and which beld P.T.C. solution. While the oubject either lookea away or closed his eyes, I put about three to five ml of the estimated threshold solution in four of the cups with a dropper and the sane anount of distilled water into the other four.

After pouring the solutions and water, I randomized the posi- tions of the cups. Then the subject was asked to taste them one at a time end sort those which contained P.T.C. from those which contained water. I told the subject that there were four of each. Sereral subjects pointed out that knowing the number of cups which contained P.T.C. solution tempted them to sort by the number of cups rather than by taste in some cases where they felt uncertain. Subjects sometimes made an arbitrary decision on the last cup so as to make two groups of four cups each, regardless of what the last one tasted like. Frequent variation of the number of cups containing 
F.T.C. could easily control this problem.

During the test the subject had a full cup of distilled water to drink. The subject was told to swish the solutions around in his mouth Ena not to swallow them quickly. Each person took a arink of aistilled water after any cup that he thought contained P.T.C. to minimize the afterteste of the solution.

If the person achieved an error-free sorting I assumed that he perceived the P.T.C. solution as different from water, and he followed the same procedure with the next weaker solution until he could no longer sort accurately. If he sorted three pairs of cups correct?y and one incorrectly, he could sort again at that number and try to correct the result. If he succeeded the second time, I accepted his perfornance and he went on to the next weaker solution.

If the eubject could not sort the tumblera he tried the next higher concentration until he succeeded. If he could not distinguish even solution No. 1 , his threshold was recorded as $<1$. Otherwise, I gave him the highest solution number at which he could distinguiah the solution from water as defined above.

\section{Possible Misrepresentation of Taste Sensations}

Successful use of the sorting technique requires considerable cunning on the part of the experimenter. I found that some of the subjects responded to the test situation in ways which made experimental control difficult to maintain. The most frequent source of response bies was the assignment of values or status by the subjects to either the taster or non-taster reactions. Although I repeatedly 
assured my subjects that a taster was no "better" than a non-taster, many still feared that they could "flunk" the sorting test. Siblings sometimes competed for the honor of having the highest or lowest threshold. Some persons tried to watch while the solutions and water. were placed in the cups, and children occasionally tried to signal their siblings whether the sorting.was correct. The only defense the experimenter has against response bias is to devise a system of coding the cups (described below) which will confuse the subject if he feels inclined to misrepresent his response. The experimenter unust also closely watch the subject and the rest of the family during each test. I could often surmise when the subjects were trying to identify the color code of the cups.

The Color Code

To minimize response bias, I used a color coding system to distinguish cups containing P.T.C. solution from those containing water. The cups, were yellow, green, orenge, and blue in color: The basic scheme assigned two colors for P.T.C. and two for water. For example, green and yellow might hold P.T.C. while orange and blue held water. I could easily vary this system without confusing myself. If I thougit a subject became aware of a certain color scheme, I discarded that set of cups and introduced a fresh set using a differ. ent combination of colors, such as green and blue to indicate P.T.C. and yellow and orange for water. Frequent changes in the color code confused not only the subject who was being tested but also other family members who were watching. 


\section{Changing Cups}

I used the same set of cups for more than one sorting test only If the subject was moving from a weaker to a stronger P.T.C. solution. This procedure assumed thrt minute amounts of a weaker solution remaining in the cup from a previous sorting would not interfere with the subject's ability to taste a stronger solution. However, if the subject was moving from a stronger to a weaker solution, the presence of even a small amount of the stronger solution wight enable him to taste the weaker one when he would not normally be able to do 80 . In the second case, the cups were changed for each sorting test to eliminate the possibility of establishing an erroneously high threshold solution number.

\section{Summary of Testing Techniques}

The serial dilution technique and the sorting tests require much more time than the crystal methods, but their benefits more than conpensate. Given proper care of the solutions to prevent deterioration and sufficient safeguards against response bias, the 8-tumbler sorting test provides a reliable means of determining whether a subject can really taste a given solution. This kind of control is absolutely necessary in any study dealing with a phenomenon as notoriously variable and subject to suggestion as taste perception. In the present study, the close fit of the data to the predictions of the simple recessive hypothesis suggest that the controls exercised were sufficient. 
iII. ANALYSIS OF DATA

Operational Definitions of Taster and Non-taster.

The introduction of the Harris and Kalmus technique hes created a difficulty in operationally defining the terms taster and nontaster. The terns were developed when all testing was done with crystals. This method can only yield two classifications--taster or non-taster. The serisi dilution method produces a continuous distribution of taste thresholds and shows that only a small percentage of persons are unable to taste P.T.C. Non-tasting consitutes only one extreme of the distribution, and the terms high and low sensitivity taster would more accurately fit the situation. However, taster and non-taster are so firmly entrenched in all literature on P.T.C. research that they will be retained in this paper but will not be used in as restrictive a sense.

The use of only two classifications presents a problem in dividing the threshold distribution curve. Traditionally one particular antimode--the class which constitutes the low point between the two modes--has been taken as the dividing line between the taster and nontaster phenotypes. The respondents whose thresholds cluster around the smaller mode (centering around solution lio. 1 or No. 2) represent the homozygous recessives--the non-tasters. The respondents whose thresholds clusters around the larger mode (centering, around solution. Nos. 8 or 9) represent the heterozygotes and the homozygous dominants--the tasters. Unfortunately, a total separation rarely exists between the two clusters in the distribution; a few measurements 
always fall in the artimodal class. Misclassification of some of the persone whose thresholds fall at or near the antimode is inevitable. Penrose. (1951) estinates that this misclassification is about $1 \%$. In each study the experimenter must decide where to cut the distribution. Assignment of the antimodal class itself to either the taster or non-taster classification is arbitrary (Earris and Kalmus, 1951; Des, 1956; Das, 1958). In the present study, solution No. 5 constitutes the antimodal class and has been included in the non-taster category. This classification follows the precedents set by Kalmus (1.958) in a study of 212 unrelated individuals and Pons (1960) in a study of 177 sib-pairs. Therefore, for purposes of this study, the term non-taster $(\bar{t})$ will include all individuals who cannot taste soiution Fo. 6. Their actual thresholds may vary fron $<1$ throligh 5. The tern taster $(\bar{T})$ will include sll individuals who can taste solution No. 6 . Their actual thresholds may vary from 6 through 14. The symbols $t$ and will stand for the non-taster and taster alleles respectively, while the symbols $\bar{t}$ and $\bar{T}$ will represent the. non-taster and taster phenotypes respectively.

\section{A Method of Analysis Not Used in the Present Paper}

Snyder's Method. The standard method of verifying the simple recessive hypothesis in regard to any trait is called the single autosomal gene substitution method and was developed by Snyder in 1932. This procedure was not used in the present peper because it contains statistical flaws. Snyder first calculated frequencies for the taster and non-taster genes. He then predicted the expected num- 
bers of non-taster children for the mating types taster $x$ taster, taster $x$ non-tester, and non-taster $x$ non-taster and compared the values with the observed numbers of non-taster children from these matings in the sample. The difficulty with the method is that it can Give misleadingly large values of chi-square in some cases. The explanetion. of the aberrant results wes that chi-square is applicable only to a sample of independent objecta. Children in the same family are not independent samples, they are correlated. Other tests had to be developed to circumvent the problems raised by Snydex's approach.

Two Methods of Analysis Used in the Present Paper

Fisher's Method. Fisher's method (after Race and Sanger, 1954) uges the family not the individual. child as the independent sampling unit to which chi-square could be validly applied. Thus he tested the simple recessive hypothesis by comparing the observed and expected numbers of families (a) having no recessive children and (b) having at lesst one recessive child. Fisher obtained his expected frequencies in the following manner. First, essuming the simple recessive hypothesis to be valid, he estimated the frequencies of the taster and non-taster genes. Next, using these gene frequencies, he calculated the probabilities that the taster parents involved in the mating types taster $x$ taster and taster $x$ non-taster would be either heterozygous or homozygous. Jsing these probabilities about the genotypes of the parents and the Mendeilan ratios to preaict what kinds of offspring such matings could produce, he determined the expected 
number of families having non-taster children for each of the two mating types-tastex $x$ taster and taster $x$ non-tagter. The expected and observed numbers of families were then compared by calculating chisquare in the usual way. A simple variant of Fisher's method has been proposed by Smith (1956). He modified the calculation of the chisquare by uaing the variance of expected the number of families containing at least one non-taster child as the denominator. Smith's method has been followed in this paper as a check on the results produced by Fisher's method.

Smith's Recessives Estimation Method. A major pitfall in Fisher's method is the asaumption of the validity of the simple recessive hypothesia in the estimation of the gene frequencies. If this estimate is faulty, error may be introduced from the start. Smith devised a means to test the simple recessive hypothesis without inroking estimates of gene frequencies. His method attempts to predict the number of non-taster children in sibships of various sizes using Mendel's ratios. To do this he first restricts his analysis to only those femilies which contain at least one non-taster child. This restriction limits the anaiysis to parents of known genotype because the production of non-taster children indicates that both taster parents are heterozygous; non-taster parents of course are homozygous recessives. He can then calculate the expected number of non-taster offopring from the two mating types=-taster $x$ taster and taster $x$ non-taster--using simple Mendelian ratios.

Interrelationship of the Hethods of Analysio. The two analytical methods employed here give two different views of the data. 'lhe 
methods supplement one another very well. Fisher's method suffers because it must estimate gene frequencies, but the use of Smith's method in conjunction with Fisher can indicate whether the estimated frequencies are correct. The application of two different analytical techniques to the data gives much more confidence in the conclusions. In the present study, the conclusions reached about the simple recessive hypothesis will be much more rellable for having been drawn on the basis of two independent tests. A further advantage to the use of both methods is that they may reveal discrepancies resulting from the small sample size in the present case. 
FOOTNOTES

${ }^{1}$ No published literature indicates that dietary hajits or preferences have any effect on the taste acuity. 
CHAPTER III

BESULTS

I. BASTC DATA

The Taste Threshold Distribution

The taste threshold distribution for the entire sample of parents and children is given in Figure 1. Among the 70 parents 17 (24\%) were non-tasters; among the 106 children 28 (26\%) were nontasters. Solution No. 5 constitutes the antimode between the two modes. kollowlng the precedent set by Kalmus (1958) persons with thresholds falling at solution No. 5 have been included in the nontaster category.

Comparison of the Taste Threshold Distribution by Age and Sex

Distribution of Tasters and Non-tasters emong the Parents.

rable II shows the results of the test of independence applied to the frequencies of the taster and non-tester phenotypes among the 35 mothers and 35 fathers. The test reveals no significant sex difference between the paternal and maternal groups with respect to the relative proportion of tasters and non-tasters. 

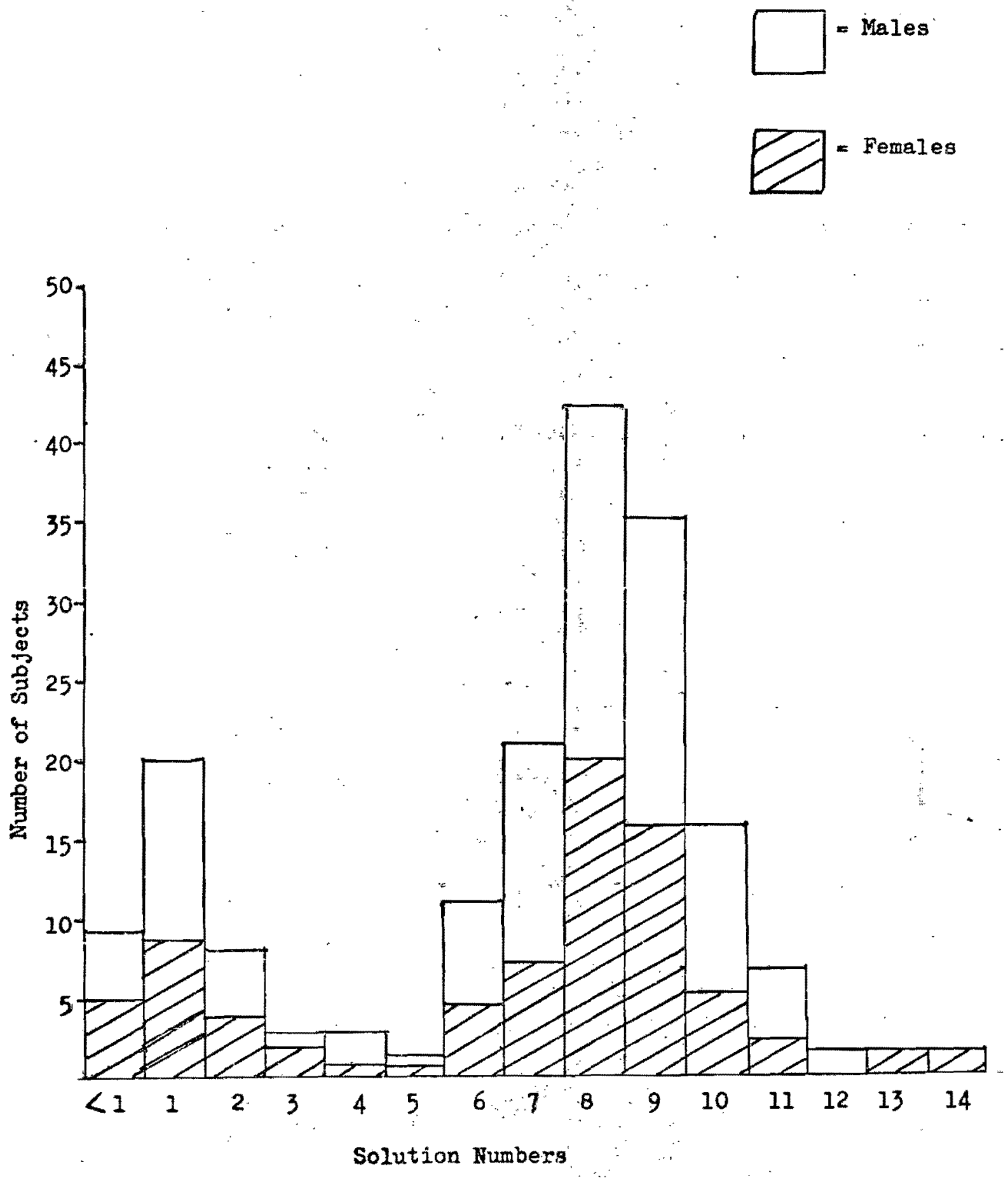

Figure 1. Teste threshold distribution of the entire sample. 
TABIE II

TEST OF INDEPENDENCE FOR TEE RROPORTIONS OF

MALE ABD FEMALE TASTEAS AND NON-TASTERS

AMONG THE BEVENTY PARENTS

\begin{tabular}{|c|c|c|c|c|c|}
\hline & \multicolumn{2}{|c|}{ Tester } & \multicolumn{2}{|c|}{ Non-taster } & \multirow{2}{*}{ Total } \\
\hline & Obsezred & Expected & Observeä & Expected & \\
\hline Mother & 29 & .26 .5 & 6 & 8.5 & 35 \\
\hline iathex & 24 & 26.5 & 11 & 8.5 & 35 \\
\hline Potal & \multicolumn{2}{|c|}{53} & \multicolumn{2}{|c|}{17} & 70 \\
\hline
\end{tabular}

Two-Hay Analysis of Tariance. It has been suggested that both age and eex may influence the acuity of taste fox P.T.C. (Harris and Kalmus, 1962; Glanville, Kaplan, and Figcher, 1964). To determine the possible influence of these factors on the present sample, a two-way analysis of variance was performed to detect sex differences, child/ adult differences, and the possible interaction of these variables in the teste threshold. As shown in Table III, no such differences were found. 
TABLE III

TWO-WAY ANAIYSIS OF VARIENCE: MAIE/FEMLIE AND ADULI/CHILD P.T.C. TASTE THRESHOLDS

\begin{tabular}{|l|r|r|r|r|c|}
\hline $\begin{array}{l}\text { Source of } \\
\text { Variation }\end{array}$ & SS & D.F. & MS & F Ratio* & P \\
\hline Sex & 8.03 & 1 & 8.03 & $<1$ & $>.05$ \\
Adult/Cnild & 1.69 & 1 & 1.69 & $<1$ & $>.05$ \\
Age x Sex & 16.02 & 1 & 16.02 & 1.34 & $>.05$ \\
\hline Within & 2049.21 & 172 & 11.89 & \\
\hline
\end{tabular}

*F $\geq 3.90$ aignificant at .05 level of confidence.

\section{Estimstion of the Gene Frequencies}

- The gene frequencies have been calculated from the parental sample. Since the mothers and the fathers do not differ significantiy with respect to relative proportions of tasters and non-tasters or diatribution of taste thresholds, the entire parental data have been pooled in estimating the gene frequencies. The frequencies of the taster allele (T) and the non-taster allele ( $t$ ) are obtained thus: (1) the frequency of the recessive $t$ allele in any population is the square root of the proportion of phenotypic non-tasters; (2) the frequency of the T allele is 1 - frequency of $t ;$ (3) population size multiplied by the respective proportions yields the respective frequencies. The calculations depend on the taster phenotype being inheritea as a Mendelian dominant character with complete dominance over the non-taster phenotype (Race and Sanger, 1954: 157). If $\mathrm{p}$ - the 
frequency of the $T$ gene and $q=$ the frequency of the $t$ gene, the frequencies of the taster and non-taster genes in the population represented by the 70 parents are found. to be respectively,

$$
p=0.5072 \text { and } q=0.492 B \text {. }
$$

These eatimated gene frequencies form the basis of the genetic analyses to follow. Among the children, the gene frequencies as estimated by the same method are $p=0.5497$ and $q=0.4503$.

\section{Phenotypic Composition of the 35 Families}

The phenotypic composition of the 35 families grouped according to mating type appears in Table IV in the form suggested by Race and Sanger (1954). Examination of tinis table shows that the one ineting between two non-tasters did indeed produce eil non-taster children.

\section{ANALYSES}

Randomness of Netings

The randomness of the 35 sample matings has already been demonstrated in Table I (see p. 16). This confirmation makes it possible to proceed with further analyses which are valid only if the condition of random mating can be satisfied. 


\section{TABLE IV}

SUMMARY OF THE PHENOTYPIC COMYOSITION OF THE THIRTY-FIVE FAMILIES WITH 106 CHILDREN

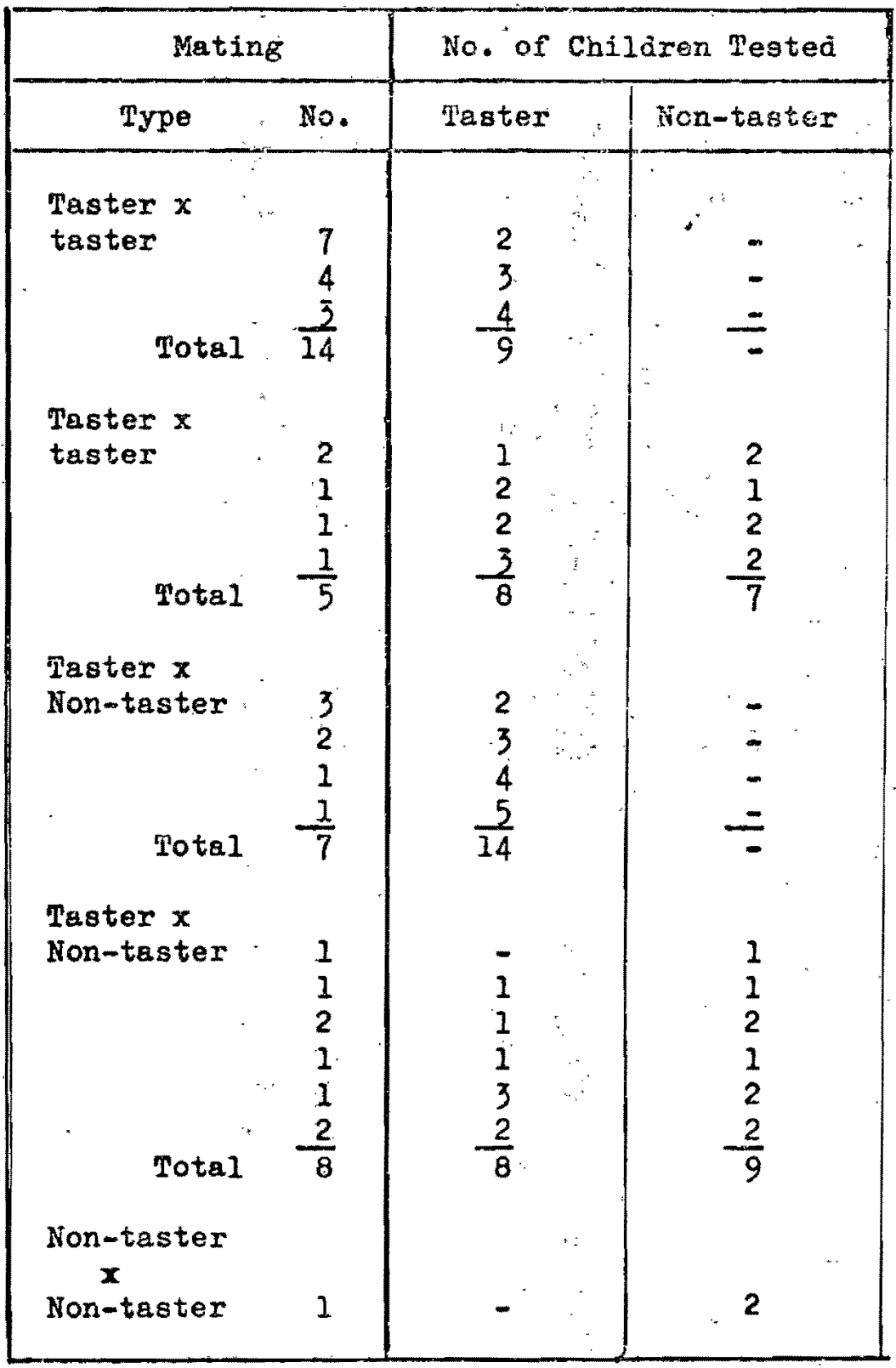


Pishex's Method of Analyass

In order to determine whether the number of families containing no non-taster children and the number of families containing at least one non-taster child agree with the expected frequencies, Fisher's method wes applied (after Race and Sanger, 1954). For each of the two phenotypic mating types-- $\bar{T}, x \cdot \bar{t}$ end $\bar{T} x, \bar{T}$ - the families were first divided Into two groups: those having all taster children and those haring at least one non-taster child. The mathematical expressions used to derive the expected frequencles of famflies containing all taster children are taken from Race and Sanger (1954) and are set out in (a) and (b) below.

(a) Mating of the type $\bar{T} \times \bar{t}$.

In matings of the type $\overline{\mathrm{T}} \mathrm{x}^{-\bar{t}}$, the probabiliti that all $\mathrm{s}$ sibs of a sibship are tasters is given by the formula:

$$
P=p /(p+2 q)+\left(1 / 2^{c}\right)(1-p / 2 q) \text {. }
$$

(b) Matings of the type $\bar{T} \times \bar{T}$

In matings of the type $\bar{T} \times \bar{T}$, the probability that all oibs $c$. of a sibship are tasters is given by the formulas

$$
P=\left[1-\left[2 q /(p+2 q)^{2}+\left(3 / 4^{c}\right) 2 q /(p+2 q)^{2}\right]\right] \text {. }
$$

For each of the two mating types, the probability that a sibship contains at least one non-taster child = I - P. It should be noted that "p" = the proportion of dominant $T$ alleles and "q" = the proportion of recessive $t$ alleles (see 1,. p. 35). It should be clarified here that $c$ represents the number of children in a family who were actually tested and may at times be less than the number of children actually existing (see Section I, Chapter II). The summary of the analysis is 
set out in Tables $\nabla$ and VI。

Whe columns of Tables $V$ and VI have been obtained in the following narnex. First, from expressions. $(i),(1 i)$, and (11i), the probaollities of all sibs being tasters in sibships of various sizes have been computed, assigning successively the values $1,2,3$, and so on to c. Next, maliplication cf each value of the probability by the corresponding number of sibships of each size in column 2 yields the values of column 3. Thas column $5=($ column $2-$ column 3$)$, and column 6 a (column $2-\operatorname{col} u m n$ 4). The variance of the expected numbers of families containirig at least one non-tagter child have been obtained in the manner described by Smith (1956) and are shown in column 7. It should be noted that, when expected cell sizes in Tables $V$ and VI were less than five, adjoining rows were merged for the computation of chi-square. Since nearly all expected cell sizes were less than five, all rows were merged and a single chi-square calculated for each mating type from the bottom row of each table.

Teble VII summarizes the test for goodness of fit for both mating types separately and jointly. The $\chi^{2}$ value has been computed by the formula $x^{2}=\sum$ (observed - expected $)^{2} /$ expected. The results show a very good fit to the predicted frequencies. This close agreement of observed and expected frequencies gives strong support to the simple recessive hypotheais. 
TABLE V

SULLALX OF THE ANALYSIS OF THE $\bar{T} \times$ F FAIIIES

\begin{tabular}{|c|c|c|c|c|c|c|}
\hline \multirow{2}{*}{$\begin{array}{l}\text { Sibship } \\
\text { Size c } \\
\text { (1) }\end{array}$} & \multirow{2}{*}{$\begin{array}{c}\text { Total No. } \\
\text { Stbships } \\
\text { (2) }\end{array}$} & \multicolumn{2}{|c|}{$\begin{array}{l}\text { No, of Sibsinips } \\
\text { (iil Sibs Tasters) }\end{array}$} & \multicolumn{3}{|c|}{$\begin{array}{l}\text { No. of Sibships } \\
\text { (At least one Sib Non-taster) }\end{array}$} \\
\hline & & $\begin{array}{c}\text { Expected } \\
\text { (3) }\end{array}$ & $\begin{array}{c}\text { Observed } \\
\text { (4) }\end{array}$ & $\begin{array}{c}\text { Expected } \\
\text { (5) }\end{array}$ & $\begin{array}{c}\text { Observed } \\
(6)\end{array}$ & $\begin{array}{c}s^{2} \\
(7)\end{array}$ \\
\hline 1 & 1 & 0.67 & 0 & 0.33 & 1 & 0.221 \\
\hline 2 & 4 & 1.91 & 2 & 2.09 & 2 & 1.000 \\
\hline 3 & 4 & 1.68 & 2 & 2.32 & 2 & 0.976 \\
\hline 4 & 3 & 1.14 & 1 & 1.86 & 2 & 0.708 \\
\hline 5 & 3 & 1.05 & 1 & 1.95 & 2 & 0.691 \\
\hline 2otal & 25 & 6.45 & 6 & 8.55 & 9 & 3.596 \\
\hline
\end{tabular}

TRELE VI

SURAFY OF THE ANALYSIS OF THE $\overline{\mathrm{T}} \mathrm{x}$ T FAMLIES

\begin{tabular}{|c|c|c|c|c|c|c|}
\hline $\begin{array}{c}\text { Sibship } \\
\text { Size c }\end{array}$ & Total No. & \multicolumn{2}{|c|}{$\begin{array}{c}\text { No. of Sibships } \\
\text { Sibships } \\
\text { (Ali Sibs Tasters) }\end{array}$} & \multicolumn{4}{|c|}{ No. of Sibships least one Sib Non-taster) } \\
\cline { 2 - 7 }$(1)$ & $(2)$ & $(3)$ & $(4)$ & $(5)$ & $(6)$ & $(7)$ \\
\hline 2 & 7 & 5.67 & 7 & 1.33 & 0 & 1.082 \\
3 & 7 & 5.24 & 4 & 1.76 & 3 & 1.319 \\
4 & 4 & 2.81 & 3 & 1.29 & 1 & 0.837 \\
5 & 1 & 0.67 & 0 & 0.33 & 1 & 0.222 \\
\hline Total & 29 & 14.39 & 14 & 4.61 & 5 & 3.460 \\
\hline
\end{tabular}


TABIE VII

SOMMARY OF ANALYSIS PY FISHER'S YETHOD

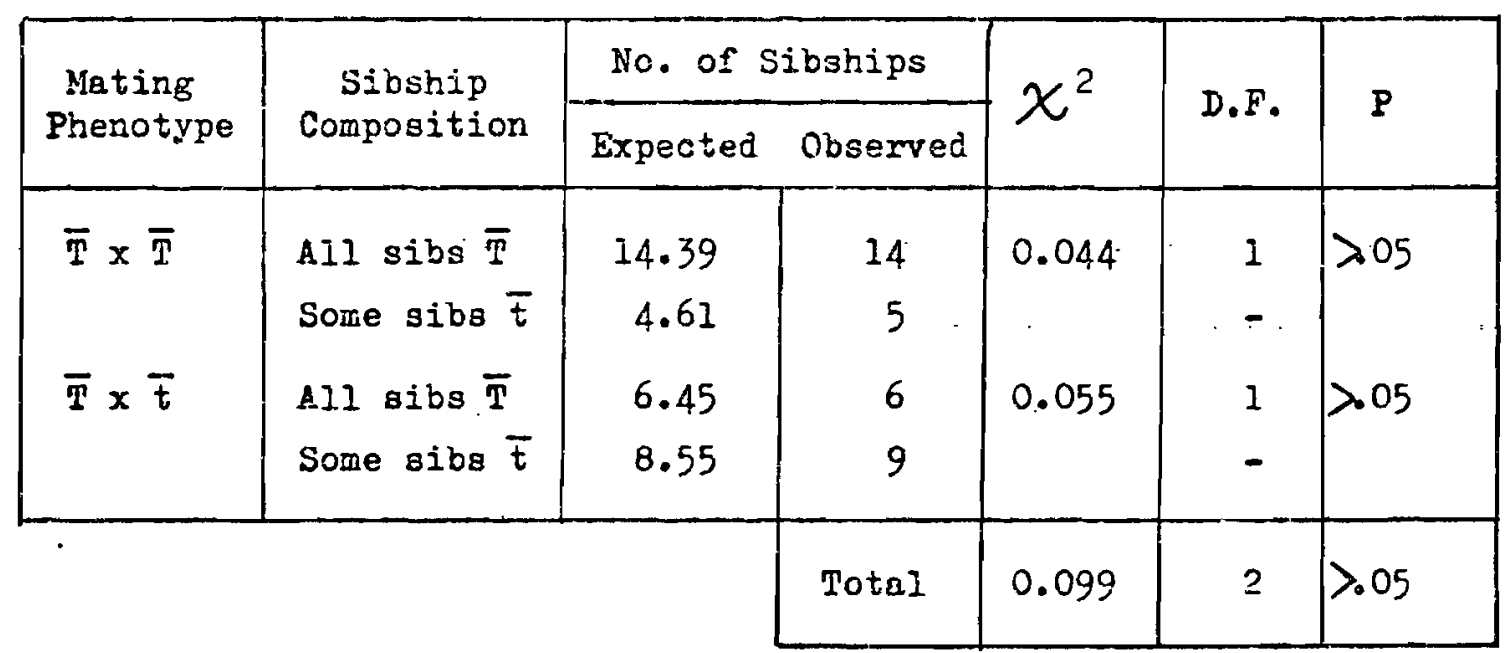

As a check on the results obtained by Fisher's method, the procedure followed by Smith (1956) has been followed. Ihis method calculates $x^{2}=\sum$ (observed - expected $)^{2} /$ variance for families containing at least one non-taster (see Table VIII).

TABLE VIII

SMITH'S VARIATION OF FISHER'S METHOD: SUMARY

\begin{tabular}{|c|c|c|c|c|c|c|c|}
\hline \multirow{2}{*}{$\begin{array}{c}\text { Mating } \\
\text { Phenotype }\end{array}$} & \multirow{2}{*}{$\begin{array}{c}\text { Sibship } \\
\text { Composition }\end{array}$} & \multicolumn{2}{|c|}{ No. of Sibships } & \multirow{2}{*}{$\mathbf{s}^{2}$} & $x^{2}$ & D.F. & $P$ \\
\cline { 4 - 7 } & Expected & Observed & & & \\
\hline $\bar{T} \times \overline{\mathrm{T}}$ & Some sibs $\overline{\mathrm{t}}$ & 4 & 4.61 & 3.460 & 0.108 & 1 & $\geqslant 05$ \\
$\overline{\mathrm{T}} \times \overline{\mathrm{t}}$ & Some sibs $\mathrm{t}$ & 9 & 8.55 & 3.596 & 0.084 & 2 & $\geqslant 05$ \\
\hline
\end{tabular}

The results of Fisher's method and Smith's modification of it show very similar outcomes. 
Sinth's Pecessives Estimation Method

The following method for testing segregation ratios in fantly data is also given in Smith (1956). - It serves as an independent check on the results reported above beceuse it requires no estimation of gene frequencies. The purpose is to predict the exact number of nontestex chiloren in sibships containing at least one non-taster child. The test hegins with the separation of families containing no nontaster children from those containing at least one non-taster child. As was discussed Chapter II, Section III, this limits the analyais to families where the genotypes of the parents can be known with reasonable certainty.

For taster $x$ taster natings which produced at least one nontaster child, the formulae for the number $\left(A_{c}\right)$ of non taster children for one sibship of gize $c$ and the variance $\left(B_{c}\right)$ of that number are uritten

$$
A=\frac{(1 / 4) c}{1-(3 / 4)^{c}}
$$

and, $\quad B_{c}=A_{c} \frac{3+c}{4}$

after obtaining the proportion $A_{c}$, multiply it by the total observed number of sibships of size c which contain at least one non-taster $\left(M_{0}\right)$ to find the expected number of these sibships. The correspondIng variance of this number if found by multiplying $M_{c}$ by $B_{c}$. For taster $x$ non-taster families containing at least one nontaster child, the formulae are written. 
and,

$$
b_{c}=a_{c} \frac{1+c}{2}
$$

The computations are the same as for the $\bar{T} \times \bar{T}$ families.

The numberical values of expressions (iv), (v), (vi), and (vil) are set out in tables IX and $X$. Both tables have a single chi-square calculated from the botton row of each table. As suggested by Smith $\dot{X}^{2}=\sum$ (observed - expected $)^{2} /$ variance. The results for each mating type show a close fit to Mendelian expectations.

\section{FABLE IX}

OBSERVED AND EXPECTED NUMBERS OF NON-TASTER CHIIDREN

IN $\bar{T} x$ TAMILIES EACH WITH AT LEAST

ONE NON-TASTER CHILD

\begin{tabular}{|c|c|c|c|c|c|}
\hline $\begin{array}{c}\text { Size of } \\
\text { Sibship } \\
\text { c } \\
\text { (1) }\end{array}$ & $\begin{array}{l}\text { No. of } \\
\text { Such } \\
\text { Sibships } \\
M_{c} \\
(2)\end{array}$ & $\begin{array}{c}\text { No. of } \bar{t} \\
\text { Children } \\
\text { Observed } \\
\text { (3) }\end{array}$ & $\begin{array}{c}\text { No. of } \bar{t} \\
\text { Children } \\
\text { Expected } \\
\left(\mathrm{H}_{c}{ }_{c}\right) \\
\text { (4) }\end{array}$ & $\begin{array}{c}\text { Variance } \\
\text { of } \bar{t} \\
\left(M_{c} B_{c}\right) \\
(5)\end{array}$ & $\begin{array}{l}\left(1 \mathrm{x} \cdot x^{2}\right) \\
(6)\end{array}$ \\
\hline 2 & 0 & $-\infty$ & - & - & $\cdot$ \\
\hline 3 & 3 & 5 & 3.89 & 0.7 .89 & \\
\hline 4 & 1 & 2 & 1.46 & & 2.243 \\
\hline 5 & 1 & 2 & 1.64 & 0.592 & .. \\
\hline Totel & 5 & 9 & 6.99 & 1.801 & $2.243(1 \mathrm{D} . \mathrm{F})$. \\
\hline
\end{tabular}


TABLE $X$

OBSERVED AND EXPECTED NUMBERS OF NON-TASTER CHILDREN

IN $\bar{T} \times \bar{t}$ FAMILIES EACE WITH $\triangle T$ IEAS'T

ONE NON-TASTER CHILD

\begin{tabular}{|c|c|c|c|c|c|}
\hline $\begin{array}{c}\text { Size of } \\
\text { Sibship } \\
\text { c } \\
\text { (1) }\end{array}$ & $\begin{array}{c}\text { No. of } \\
\text { Such } \\
\text { Sibships } \\
M_{c} \\
(2)\end{array}$ & $\begin{array}{l}\text { Wo. } \bar{t} \\
\text { Children } \\
\text { Expected } \\
\text { (3) }\end{array}$ & $\begin{array}{l}\text { No. } \bar{t} \\
\text { Chiidren } \\
\text { Observed } \\
\left(m_{c}{ }^{q_{c}}\right) \\
(4)\end{array}$ & $\begin{array}{c}\text { Variance } \\
\left(\operatorname{mos}_{c}{ }^{2}\right) \\
(5)\end{array}$ & $\begin{array}{l}\chi^{2} \\
\left(I D_{0} F_{0}\right) \\
(6)\end{array}$ \\
\hline 1 & 1 & 1 & 1 & 0.0007 & \\
\hline 2 & 2 & 1 & 2.67 & .0 .666 & \\
\hline 3 & 2 & 4 & 5.14 & 1.470 & .0856 \\
\hline 4 & 2 & 4 & 4.27 & 1.564 & \\
\hline 5 & 2 & 6 & 5.16 & 2.164 & \\
\hline Total & 9 & 16 & 18.24 & 5.864 & .0856 (1 D.F.) \\
\hline
\end{tabular}

The results of the research which have been summerized in this chapter indicate that the data closely fit the predictions of the simple recessive hypothesis for non-tasting. No significant deviations from expectation were discovered by any of the analytical methods employed. 


\author{
CHA PTER IV \\ DISCUSSION, SUMMARY, AND CONCLUSIONS
}

I. COMPARISON OF THE PHESENT STUDY WITH SIB-PAIR

AND OTHER FAMILY STUDIES

\title{
Sib-Pair Studies
}

Throughout this investigation the data have shown a consistent pattern strongly supporting the simple recessive hypothesis for nontasting. This outcome appears to be at odds with other reported results (Das, 1956; Das, 1958; Harris and Kalmus, 1951). The study by Harrio and KaImus involved 384 sib-pairs. The authors used the ailution scale and sorting test they had devised earlier (Harris and Kalmus, 1949b) to determine the thresholds of the subjects. It should be noted here that a sib-pair study differa from a full family study in that only the children are considered. Sib-pairs can be divided. into four classes: (1) both sibs are testers, (2) the older sib tastes and the younger does not, (3) the younger sib tasts and the older does not, and (4) both Eib are non-tasters. Harris and Kalmus tested two independent hypotheses with their sib-pair data. The firat was that the phenotypic constitution of the sib-pairs depends on the inheritence of non-tasting as a simple recessive trait. To test this bypothesis, estimates of gene frequencies must be obtained. Herris and Kalmus estimated the frequency of the non-taster allele $(t)$ and the tagter allele ( $(\mathrm{P})$ in the following manner: (1) the frequency of 
the recessive $t$ allele was equal to the square root of the proportion of phenotypic non-tasters in the sib-peix sample, and (2) the frequency of the $T$ allele was 1 - the proportion of $t$. Uaing the estimates of gene Exequencies the proportions of the four phenotypic types of sib-pairs in the sample should be:

$$
\begin{gathered}
(1-q)\left(4+4 q-3 q^{2}-q^{3}\right) / 4: q^{2}(1-q)(3+q) / 4 \\
: q^{2}(1-q)(3+q) / 4: q^{2}(1+q)^{2} / 4
\end{gathered}
$$

where $q=$ the proportion of the nor-tagter allele ( $t)$. The second hypothesis wes that the phenotypic constjtution of the pairs was due to chance and not to any hereditary factor." In this case no gene frequencies are used. The expected proportions of sib-peirs are given by the foilowing ratios:

$$
(1-f)^{2}:(1-f):(1-f): f^{2}
$$

where $f=$ the total frequency of non-tester sibs in the sample. 1

Earris and Kalmus found that their data did not fit the predictions of aither hypothesis. However, because the $\chi^{2}$ for the "chance" hypothesis was smaller than that for the simple recessive hypothesis, they concluded that the data were "closer to" the fomer. In general the observed frequencies fell about tidway between the numbers predicted by the genetic hypothesis and the "chance" hypothesis. Harris and Kalmus stated that the departures of their data from the simple recessive hypothesis stemed from a considerable misclassification of the genotypes of persons whose thresholde fell near the antimode; they did not elaborate on the possible sources of this misclassifica- 
tion. When the responses of the borderlire subjects (those having thresholds of 5,6, and 7) were eliminated, the data fit the simple recessive hypothesis very well. On the assumption that the taste thresholds distributions of tasters and non-tasters form two overlapping Gausian curves, they concluded that the number of persons assigned to the wrong genctype mist. be greater than had heretofore been believed.

The study by Des, (1956) of 845 sib-pairs gave somewhat different results. Although the data proved discordant with the predictions of both the simple recessive and "chance" hypotheses, the $\chi^{2}$ for the genetic hypothesis was smaller. Again, elimination of taste threshold responses near the antimoce (where overlapping of the distributions vould produce the greatest nusber of persons assigned to the wrong genotype) brought the data into accord with the predictions of the simple recessive hypothesis, Like Harris and Kalmus, Das did not attemet to explain what factors migts cause misclassification to the intemediate types.

Summary of the Sib-Peir. Studies. The large scale sib-pair studies conducted by Harris anả Kalmus, and Das, have produced results which do not agree with efther the simple recessive hypothesis or the "chance" hypothesis. Departure of the data from the simple recessive hypothesis appear to spring from the fact that no absolute separation exists between the taste threshola distributions of tasters and nontasters. If the sssumption that the antimodal aree represents the overlap of two Gaussian distributions is valia, then persons whose thresholds fall at or near the antimode could be either non-tasters 
(homozygous recessives) oi tasters (heterozygotes or homozygous dominants). The asgignment of persons to the wrong categories could lead to errors in the estimates of gene frequencies and hence to departures from the simple recessive hypothesis.

\section{Effects of Misclassification}

If considerable misclassification occurs, then a number of consequences may follow.

(1) In a non-taster $x$ non-taster mating, the misclassification

of a taster parent as a nor-taster could cause that mating to show taster children. 'this result is directly contrary to the predictions of the sinple recessive hypothesis.

(2) In the use of Fisher's mthod, errora in classification could affect the outcome at several different points. First, the estimates of gene frequencies depend on the operational definitions of taster and non-tasters. If persons are assigned to the wrong categories, the gene frequencies may appear to bo higher or lower than they really are. Further, this error may possibly be magnified by successive steps in the computation. Second, the assignment of parents to the wrong categories would produce misclassification of the mating type. This could be revealed in the numbers of matings showing either all taster children or some non-taster children. For instance, the classification of a non-taster parent as a taster would change a taster $x$ non-taater mating to taster $x$ taster. If the other parent were a homozygous taster, no unugial results would appeer because all 
children would be tastere in any case. However, if the second parent were heterozygous, one half of the offspring could with confidence be predictied to be non-tasters by chance alone. This might exroneously edd another family showing at least one nontaster child to the totals for the $\bar{T} x \bar{T}$ matings, which, in turn, could lead to misleadingly high chi-squares (absence of fit) when Fisher's method is applied." The opposite problem would be encountered if a taster parent were misclassified as the nontaster in a $\bar{T} \times \bar{t}$ mating. In this case, there could be a shortage of families containing non-taster children.

(3) Since Smith's method uses no estimates of gene frequencies, classification errors mjght not be magnified as much as they could be in Fisher's method. However; misclassification of parents could produce unexpected numbers of non-taster children in subships of various sizes. For example, if a non-taster parent were classified as a taster in \& $\bar{T} \times \bar{T}$ mating, the family could show too many non-taster offepring. The opposite would. occur in $\bar{T} \times \bar{t}$ matings where the non-taster parent was really a taster. Such a family wight show too few non-taster children. Any or all of these effects could skew the data so that they did not fit the simple recessive model. The possible sources of misclassification will be more fully discussed in a later section.

\section{Family Studies}

Das's stidy (1958) of 126 families, including parents and their children, covered the same families as his aib-pair study. He found 
that the simple recessive hypothesis roughly fit the material when it was analyzed by Fisher's and Snith!s wthods, but that the trend of the data was "fluctuating", showing good agreement for some tests and significant discrepancies for-others. He hypothesized that the expression of the taster gene might be subject to ontogenetic variation. However, he. overlooked his. own findings. in the sib-paix study suggesting considerable misclasgification of internediate phenotypes. The inconaistent nature of the non-Mendelian variations in the data might well stem from misclassification of parental phenotypes resulting in the assignment of matings to the vrong types.

Merton (1958) aiso attempted to test the simple recessive hypothesis. She gathered two different samples of subjects. The first incluajed 266 unrelated inaividuals drawn fron the University of 0sio in Norway. This group was used to estimate the gene frequencies. The second sample was a group of 60 families, presumably from Norway. When the families were analyzed with Fisher's method, the results appear to confirm the simple recessive hypothesis. However, this outa come presents more puzzles than it solves. Merton used the Harris and Kalmus dilution scale and the sorting technique with one alteration. For reasong left unstated, Merton modified the accepted method by using solution No. 3 as stcck No. 1. Her stock NC. I thus contained $0.325 \mathrm{~g}$ of P.T.C. In one liter of water instead of $1.3 \mathrm{~g}$ per liter. Surprisingly, the antimode still fell at solution No. 5. Solution No. 5 on the Farrie and Kalmus scale contains $0.8125 \mathrm{~g}$ of P.T.C. per liter of water; in Merton's study it contained $0.2031 \mathrm{~B}$ per liter, corresponding to Earris and Kalmus solution No. 7. The ques- 
tion is, how could she still find an antimode at No. 7 when every other study has placed it at or near No. 5? There is no answer avallable to this puzzle.

A second anomalous result of Merton's study concerns the relatively large percentage of persons with thresholds at 108.13 and 14. Werton's solutions No. 11 and 12 correspord to Nos. 13 and 14 on the standara scale. Yet Merton found a total of 29 persons out of 266 (1i\%) registering thresholds of No. 11 and above. In Das's (1956, 1958) studies a total of 255 and 489 children were tested and not a single person was found with a threshold at No. 13 or No. 14. Kalmus (1958) in a study of: 212 unrelated individuals in England found only one person with a threshold of No: $13(0.4 \%)$ and none at No. 14. In the present" study, out of a sample" of 70 adults and 106 children; two persons $(2 \%)$ showed thresholds of 13 or 14 . It is possible that these variations in the number of highly sensitive tasters reflect innate population differences. Das's work was done in India, and Kalmus worked with an English sample. Possibly some unknown genetic or environmental influence operates on the Norwegian population to appreciabiy raise the acuity of taste for P.T.C. When compared to sample drawn from other populations.

Summary. A series of family studies. show some support for the simple recessive hypothesis. When Harris and Kalmus a well as Das, use all their data, significant deviations from the hypothests appear. In both of these studies, the elimination of the borderline phenotypes 5. 6, and 7 from the analysis brings the results into line. This ouggests that considerable numbers of persons may be misclasoified near 
the antimode. Merton's study confirmed the gimple recessive hypothesis, but the antimode is in the wrong place. The evidance froni the present study clearly confinas the simple recesgive hypothesis. The inconsistent nature of the results clearly indicates that further investigation of this problen is needed.

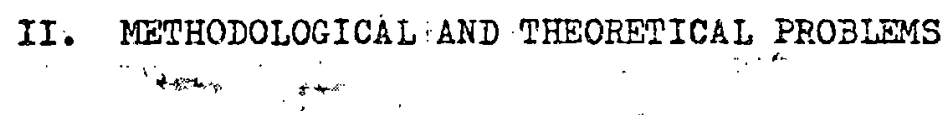

The Antimode as the Dividing Line Between Tasters and Non-tasters

- The Problem. The most persistent source of confusion and posalbie error in P.T.C. research lies in the use of the antimode to separate the taster and non-taster phenotypes. Both Das (1956, 1958) and Harris and Kalmus (1951) have found that elimination of the responses of the persons whose thresholds fell at or near the antimode brought their data into conformity with the predictions of the simple recessive hypothesis. This suggests that considerable numbers of persons whose taste thresholds were on or near the antimode may have been misclassified. The difficulty lies in the fact that a total separation rarely exists between the taster and non-taster distributions; some measurements always fall in the antimodal class. The inability to accurately separate tasters and non-tasters is a source of great confusion in genetic studies in which estimates of gene frequencies depend on the proportion of non-tasters in the sample.

The Effect of the Dilution Scale. Orerlap of the phenotypic measurements of the effectis of certain gerotypes is a comon enough phenomenon (Penrose, 1951). Frequently, the overlap is an artifact of the scale of measurement (Mckusick, 1964:58). In the case of 
P.T.C., it is possible that the standard scele employing a dilution fector of two is simply too grose to reveal the separation between the two distributiona if such a separation exists. One possibie solution to this problem is to substitute a refined linear (arithnetic) scaie instead of a logarithmic scale in the antimodal area. Subaividing the dilution steps in these ways might reveal a break between the distributions of tasters and non-tasters.

Kalmus's Method of Dividing the Distribution. Kalmus (1967) proposed that the customary method of dividing the bimodal distribution at the antimode may not be the most useful for certain genetic studies. He advocated the use of two different discriminating functions which mignt fall to the rigint or left of the antimode. If the purpose of the experiment is to make the fewest possible miatakes in the classifications of individuals, a discriminant which misclassifies equal percentages of the two subpopulations would be computed. However, if the purpose of the experiment is to calculate gene frequencies, the discriminant which misclassifies equal numbers of in-. dividuals rather than percentages of the subpopulations would be ueed.

Kalmus then uses his P.T.C. data to show how the gene frequencies obtained by his method would differ from those computed in the usual way. A possible focus of future investigation would be a re-evaluation of all the family studies of P.T.C. tasting. New gene frequencies could be computed by Kalmus's technique and the resulting data re-analyzed by Fisher's method. If this procedure brought the deviant studies into line with the simple recessive hypothesis without 
destroying the fit of studies alresdy confiming the hypothesis, the conclusion could be drawn that the customery way of dividing the distribution has been the cause of misclassification of phenotypes. Measurement Error:- One possible and very obvious source of misclassification is measurement error. This factor is generally ignored in the literature. Measurement error could change the results In two ways: (1.). thresholds could be inaccurately determined because of mistakes in the sorting test, and (2) the solutions used in testIng are not of uniform coricentration throughout the experiment. In the first case, error can bẹe quite easily controlled by re-testing of the subjects. Any discussion of measurement error in the published material on P.T.C. generally concerns itself with this aspect. The second possibility is less readly detected. As has been stated before, P.T.C. is an organic compound-which can be decompcsed by light, air, and microorgenisms especially when it is in very weak dilutions (Lutz, personal comnunication). If solutions are kept over a long period of time they may weaken, resulting in lower threshold solution numbers for persons tested later in the experiment. This kind of error might account for some of the classification problems which have plagued studies of the genetic aspects of P.I.C. tasting.

In the present experiment, stringent precautions were taken to assure the continued comparability of the solutions. The test solutions were refrlgerated to retard the growth of micro-organisms. The bottles were refilled continuously. to minimize the amount of air present. The solutions were discarded after 30 days and replaced with fresh ones. The comparability of the first and second series was 
assayed by re-testing persions with thresholds of 1,6 , and 11 . These precsutionary measures geve assurance that the test solutions were kept close to uniform throughout the experiment. The use of these techniques dià not produce a complete break between the taster and non-taster distributions as had been hoped; the antimode class contained two individuels. However, the close fit of the data to the predictions of the simple recessive hypothesis suggests that classification problems were slight. This is not conclusive evidence, but it certainly suggests that measurement error, particularly with respect to the comparability of the solutions, may be, in part, responsible for some misclessification in other studies.

The Issue of Incomplete Dominance

- Some investigators, notably Kalmus (1958) and Des (1958) have advanced the opinion that the taster allele may be incompletely dominant over the non-taster allele. They base this hypothesis on the fact that taster children from $\bar{T} \times \bar{t}$ matings had a significantly lower mean threshold than did taster children from $\bar{T} \times \bar{T}$ matings. In the present study, the mean threshold of 45 taster children from $\bar{T} \times \bar{T}$ families was compared with the mean of 32 taster children from $\bar{T} \times \bar{t}$ families. The first groups showed a mean threshold of 8.87 and the second had a mean of 7.94. This indicates that the first group, who are necessarily heterozygous, have a mean 0.93 dilution steps below that of the second group which is a mixture of heterozygous and homozygous tasters. Comparison of these two means using the " $t$ " test show this difference to be highly significant $(t=2.906 ; P<.01)$. If it 
were possible to segregate the heterozygous and homozygous tasters, there would probably be en éven greater difference between the meens. The afluting effect of the heterozyote testere from $\bar{T} x$ mating is not known. These differences are consistent with those found by Des (1958) and give further support to the hypothesis of incomplete doninance.

III. POSSIBLE SOURCES OF ONTOGEIVTIC VARIATION IN THE EXPRESSION OF THE TASTE CHAPACTER

The Influence of Age

Introduction. Assessment of the influence of age on the acuity of taste for P.T.C. must deal with geveral possible patterns of variation. Pirst is the development of teste sensitivity in the young. In this case there are two possible alternatives: (1). children are born with their taste threshold which remains unchanged throughout life, and (2) taste acuity rises as the child matures. The second developmental pattern is the behavior of the taste threshold when the child reaches maturity. Here there are three possible alternatives: if the child is born with a certain threshold, that threshold could simply remain unchanged, (2) if teste acuity rises as the child matures, the threshold could peak sometime in early edulthood and then otart to fall, and (3) taste sensitivity could rise until early adulthood, then remain on a plateau until middle age, and then begin to fall. These three possible developmental variants could be dubbed the unform, peak, and plateau patterns. The following studies utilize these different patterns in investigating the effects of age. 
Glanville's Study Gianville, Kaplan, and Fischer (1964) devised a study to determine the effects of age on taste acuity from early childhood through riddle age. The sample consisting of 308 males and 368 females ranging in age from 3 years to 55 years. The distributions of males and of females were each broken down into five year increments. (i.e., i-5 years, 6-10 yeers through 51-55 years). The tast chemical was 6-n-proplythiouracil (PROP). PROP is of the seme chemicel family as P.T.C. and shows a bimodal distribution of taste thresholds, Glanvilie et al used the Harris and Kalmus dilution technique and the sorting test. Eowever, they altered the standard procedure in two ways: (1) they used fifteen dilution steps instead of fourteen and (2) they reversed the numbering of the solutions so that No. 1 was the weakest and No. 15 the strongest.

Bramination of the mean taste thresholds for the five year age Groups showed that taste acuity increased for both males and females from the youngest individuals tested through the 16-20 year age group. After age 20, tasto sensitivity declined for both males and females. with the males deteriorating at about twice the rate of females. The decline continued steadily through age 55. This indicates a peak pattern in the development of taste acuity.

The results of Glanville's study can only be applied with reservation to P.T.C. research. The two chemicals PROP and P.T.C. may not really be comparable, even though they both generate bimodal diatributions of taste thresholds. PROP is less soluble in water than P.T.C. To make a saturated solution of PROP, $1.0212 \mathrm{~g}$ are dissolved in one liter of water; a eaturated golution of P.T.C. contains $1.3 \mathrm{G}$ 
per liter of water. Second, the mean thresholds for PROP occur at very high concentrations compared to those for P.T.C. For example, persons in the age group $46-50$ had a rean threshold which corresponds to No. 2 in the Herris and Kalmus scale. Means for other ages also are high. These differences suggest that data generated by the two substances may differ gubstantially.

The Kalmus and Trotter Study. In $1962 \mathrm{Kalmus}$ and Trotter performed a longitudins.2 study. of P.T.C. taste development in which 110 adults were re-tested for threshold after a lapse of from ten to fifteen years; the average was 13 years. The Harris and Kalmus dilution scale and sorting test was voed to determine all thresholds. The sample included 34 healthy men and 26 health women as well as 6 goitrous women. The goitrous individusls were included to determine if thyroid disease affected the rate of chenge in taste acuity. On the second testing occasion, among the 110 subjects, 27 showed the same threshold, 61 showed a lower threshold number (lower acuity), 22 showed higher threshold number (higher acuity). Ihus on the averege taste sensitivity declined in adult subjects over the ten to fifteen year interval. They reported a mean threshold deterioration in the whole sample wos $0.6182 \pm 0.1559$ threshold steps, which they considered equivalent to a mean annual deterioration of $0.0468 \pm 0.0118$ dilution steps. Contrary to the findings of Glanville et al (1964) the decline was more rapid in women than in men. Both tasters and non-tasters lost acuity although the range of change possible was obviously greater in tasters than in non-tasters. Thyroid disease appeared not to affect the rate of change in threshold. 
Unfortunately, only the age at the second testing is given so that the age at first testing could vary by as much as five years. The age range at second testing was from 33 to 75 years. Although no data on children are included, the results suggest a pattem of development of P.T.C. tasting in which a decline begins at about 18-20 years of age. Seventy-one subjects were below-age 47 when they were first tested; thirty-nine were age 48 and above. These two groups showed virtually the same annual mean threshold deterioration over the ten to fifteen year interval, suggesting that the decline is steady once it begins. A further hint that taste acuity may peak during early adulthood is also found in the data. Fifteen individuals In the sample were in their thirties at the time of second testing; they would clearly have been in their twenties when they vere first tested. Of these, fifteen, ten showed a lower threshold number at second testing, three showed no change, and two showed a higher threshold number. This suggests that taste sensitivity decreases during the twenties just as it does in later years. Clearly there. is a need for further studies of children using P.T.C. to determine the pettern of development before maturity.

Mohr's Findings. Mohr (195I) produced data which suggested a plateau pattern of taste development.. The study was conducted in Denmark using the Harris and Kalmus solution scale and sorting test. Mohr found that the average taste threshold for a group of 251 inaividuals from 16-30 years of age was significantly higher than that for a group of 44 individuals above 61 years of age. (The difference between the means was assessed by a $t$ test.) These results suggest 
that taste ecuity does not deteriorate between the ages of 16 and 30 , but, since no finer subdivisions of this age range were published by Mohr, this conclusion can not be considered certain.

Influence of Age on Trste Acuity in the Present Study. In general the data on age found in the present study auggests that the teste threshold is ecquired very eerly in life and remeins unchanged through adulthood. The possible influence of age was assessed in two ways. First, the two-way ANovA described in Chapter II, Section I anelyzed the effects of age and sex separately and simultaneousiy. The age category was simply divided into parents and children. The parents ranged in age from 28 to 65 and the children from 6 to 34 years. Parents and children showed no significant differences in threshold. There did not appear to be any sex effect elther which is contrary to the findings of both Kalmus and Trotter and Glanville et al. Second, to test whether any relationship existed between rising age of the children and taste sensitivity, a correlation was computed between the age of the children and their taste thresholds. The correlation was calculated in two different manners. First, all childxen and their thresholds were considered. The results $(r=0.01)$ showed no relationship between age and taste acuity. In the second correlation, children with thresholds of 1 and 1 were not considered. These thresholda were not included on the assumption that rising taste sensitivity would probably depend on the presence of the dominant taster gene. Persons with thresholds of $<1$ end 1 are almost certainly homozygous recessives whose taste acuity would not rise very far in any case. When the diluting effect of the certain homozygotes was 
eliminated the correlation rose only slightly $(x=0.09)$ and was stfll not significknt. These two pieces of evidence suggest but certainly do not prove that taste sensitivity to P.T.C. remains fairly uniform. Ore possible source of this uniformity lies in the fact that the developnental patterns occurring in the parents and the children could cancel one another out. The majority of the children might not have reached their full taste acuity while the adults may already be deteriorating. This could place them an opposite but about equal distance from the maximum acuity.

Summary of the Effects of Age on P.T.C. Taste Acuity. The true effects of age on sensitivity to P.T.C. are still in doubt. The data of Kalmus and Trotter and especially of Glanville et al could be interpreted as implying thet taste sensitivity rises throughout childhood until about the age of twenty and then begins a slow steady decline. The two studies show directly opposite data on the effects of age and sex combined. However, some of these differences could rest on the fact that different test chemicals were used. Mohr (1951) included no data on young children, but his findings suggested that the years between 16 and 30 constitute a plateau period in taste development. Finally, the present study suggests that no substantial change occurs in taste threshold between the ages of 6 and 65 . These findings, however, could stem from either the small sample size or from a cancelling effect due to parents and children being on opposite sides of peak taste acuity. A large study with sizeable samples of individuals at each five year age group from early childhood to late middle age is needed to deal with the true effect of age on F.T.C. acuity. 
However, a pitfall in euch a cross sectional study is that if either tasters or non-tasters have a selective advantage, the other phenotype may be underrepresented at the older age levels. With this caution in mind, the cross sectional study is the only altemative to an extensive and probably impossible longitudinal study.

\section{The Influence of Sex}

The influence of sex also problematical. The results of early studies, notably that of Bartman (1939), suggested that females were slightly more sensitive then males. Consistent and definitive proof is still lacking regarding the statistical significance of these results. Harris and Kalmus (1949b) state that the females in their sample appeared to have had a slightly higher acuity for P.T.C. than did the males, but the statistical significance of their findings was not evaluated. Other investigators, on the other hand, including Das (1956), Pons (1956), Pons (1960), and Merton (1958) have found no aex differences in P.T.C. taste thresholds.

In the present study no difference in the number of male and female non-tasters appeared. The two way ANOVA for age and aex, showed that sex--by itself or in conjunction with age--was not related to taste threshold. For the moment it mist be concluded that the influence of sex on taste sensitivity is uncertain.

\section{The Influence of Smoking}

The use of tobacco is generally believed to dull the sense of taste. Several different investigators bave failed to provide support for the common assumption that smoking would tend to decrease 
sensitivity to P.T.C. by deadening or deteriorating the taste buds. Hall and Blakeslee (1945), Falconer (1946), Pons (1956), and FreireMaia (1966) have attempted to assess the effect of smoking. Only the studies of Pons and Freire-Maia will be considered because their F.T.C. taste tests are comparable to those used in the present study. The others used methods no, longer considered valid and the comparability of their results cannot be established.

In a sample of 97 male non-smokers and 75 male smokers, Pons found no significant difference in the average taste threshold for P.T.C. among non-smokers and smokers (defined as those who smoked at least five cigarettes daily). The same result occurrea when a subseries of smokers who smoked at least ten cigarettes disly were compared to the non-smokers.

Freire-Mala defined smokers as those who smoked at least twenty cigarettes a day. Freire-Maia does not state whether a person who smoked nineteen cigarettes a day would be considered a non-smoker. This leaves the definition of non-smokers somewhat hazy. wo difference was found in the numbers of non-tasters among the smokers and non-smokers. An analysis of the average taste thresholds for smokers and non-smokers also showed no differences. It appears from these studies that smoking does not have any appreciable effect on either the number of non-tasters or upon the average taste thresholds. However, more refined experiments are needed in which persons who smoke different numbers of cigarettes a day are compared with persons who do not smoke at all. Such a scale might run as follows: 1 - 5 cigerettes daily; 6 - 10 daily $11-15$, and 60 on. Thts type of study could 
determine if smoking bas any effects on how wuch a person must smoke for such effects to occur.

Summary of Data on Ontogenetic Variation

Age, sex, and smoking are the three variables most commonly believed to affect the ability to taste P.T.C. Results fron studies on age, sex, and their interactions have produced results so contradictory that much more research is needed. Overall, smoking seems to have little if any effect on taste sensitivity, but the studies done so far have been rather crude. Studieg conducted with larger samples and more preciae definition of smokers and, non-smokers are needed.

\section{SUMMARY OF THE RESIILTS OF THE PRESENT STUDY}

The simple recessive hypothesis for non-tasting of P.T.C. had been tested on 35 families with the following results. First, the 35 matings were shown to be random. Satisfaction of this condition allowed the gene frequencies estimated from the parental sample to be used in other genetic analyses. Second, analysis of the families by Fisher's method and Sinth's modification of Fisher's method showed a good fit to the predictions of the Mendelien recessive hypothesis for the numbers of $\bar{T} \times \bar{T}$ and $\bar{T} \times \bar{t}$ femilies containing all taster children or at least one non-taster child. Whird, Smith's recessive estimation method was used to determine the expected number of non-taster children in aibships of various sizes for both $\bar{T} \times \bar{T}$ and $\bar{T} \times \bar{t}$ matings. Comparison of the observed and expected numbers showed no significant deviations from the simple recessive hypothesis. 


\section{マ. CONCLUSION}

On the basis of the data generated by this study, it must be concluded that no evidence exists for discarding the hypothesis that the inability to taste P.T.C. is caused by the action of an autosonal recessive gene in. the homozygous condition. Analysis of the sample familiea by several cross check methods fails to show oignificant divergences from the frequencies predicted by this hypothesis. These results differ from those reported for some family and sib-pair studies. These differences could spring either from the small sample size of the present study or from the use of very stringent precautions in the preparation and care of the test solutions which presumably reduced measurement error. A study with large semple size and rigit controls is clearly needed to settle the losue of the inheritance of P.T.C. non-tasting. 
FOOTNOTES

1 It should be noted here that if the gimple recessive hypothesis is valid, $f=q^{2}$. In the original article by Harris and Kalmus (1951) the symbol " $t$ " was used in place of "f". The change was made in the present paper bacause " $t$ " has already been used in a very restricted sense to stand for the non-taster allele. The notation was changed to avoid confusion. 


\section{REFERENCES CITED}

Barnicot, N.A.

1951 "Taste Thresholds of Further 18 Compounds and Their Correlation with P.T.C. Thresholds." Ann. Eugo, 16: 119-128.

Blakeslee, A.F.

1932 "Genetics of Sensory Thresholas: Taste for Phenyl-thiocarbamide." Proc, Nat. Acad. Sci.s 1.8: 220-130.

Das, S.R.

1956 "A Contribution' to the Heredity of the P.T.C. Taste Character Based" on a Study of 845 Sib-Fairs." Ann. Hum. Genetics, 20: 334-343.

Das, S.R.

1958 "Inheritance of the P.T.C.' Taste Character in Man: An Anslysis of 126 Rarhi. Brahmin Families of Hest Bengal." knn. Hum. Genetics, 22: 200-212:

Falconer, D.S.

1946 "Sensory Thresholas for Solutions of Phenyl-thiocarbamide. Results of Tests on a Large Sample." Ann. Bug.., 13: 211-222.

Fox, A.L.

1931 "On Tasteblindness." Science (Suppl.), 74: 14.

Fox, A.I.

1932 "The Relationship Between Chemical Composition and I'aste." Proc. Nat. Acad. Sci., 18: 115-120.

Freire-Maia, A.

1960 "Taste Sensitivity to P.T.C, in Samples From Three Brazilian Populations." Ann. Fur. Genetics, 24: 97-101.

Glanville, E.V., A.R: Amold and R.F. Fisher

1964 "Age, Sex, and Taste Sensitivity.": J. of Geront., 19: $474-478$.

Hall, D. and A.F. Blakeslee

1945 "Effect of Smoking on Taste Threshoids for Phenyl-thiocarbamide (P.T.C.).": Proc. Nat. Acad. Sci., 31: 390-396. 
Harris, H. and

1949a "Chemical Speciricity in Genetical Differences in Taste Sensitivity." Ann. Euge, 15: 32-45.

Harris, H. and H. Kalmus

19490 "The Measurement of Taste Sensitivity to Phenylthiourea." Ann. Eus., 15: 24-31.

Hartman, $G$.

1939 "Application of Individual Taste Differencea Towards Phenyl-thio-carbamide in Genetic Investigations." nn. Eug., 9: 123-135.

KaInus, $\mathrm{H}$.

1958 "Improvements in the Classification of the Taster Genotypes." Ann. Hum. Genetics, 22:" 222-230.

Kalmus, H. and W.R. Trotter

1962 "Direct Assessinent of the Effect of Age on P.T.C. Senoitivity." Ann. Hum. Genetic3, 26: 145-149.

Lutz, R.P.

1973 Pexsonal Commuication

McKusick, V.

1964 Buman Genetics. Prentice-Rall, Inc. Englewood Cliffa, N.J.

Merton, B.B.

1958 "Taste Sensitivity to P.T.C. in 60 Norwegian Families with 176 Children: Confirmation of the Hypothesis of Single Gene Inheritance." Acta Genetica et Statistica Medica, 8: 114-138.

Mohr, J.

1951 "Taste Sensitivity to Phenylthiourea in Denmark." Ann. Eus:, 16: 282-286.

Penrose, L.S.

1951 "Measurement of Pleitropic Effects in Phenylketonuria." Ann. Eug., 16: 134-141.

Pons, J.

1955 "Taste Sensitivity to Phenylthiourea in Speniards," Hum. Biol., 27: 153-160.

Pons, J.

1960 "A Contribution to the Heredity of the P.T.C. Taste Character." knn. Hum. Genetics, 24: 71-76. 
Race, R.R. and R. Sariper

1954 Blood Groups in Men. Blackwell Scientific Publications. Cxford and Edinbureh.

Setterfield, W., R.G. Schott and L.E. Snyder

1936 "Studieg in Human Inheritance. XV. The Bimodality of the Threshold Curve for Taste of Phenyl-thio-carbamide." Ohio J. Sci.36: 321-324.

Smith, C.A.B.

1956 "A Test for Segregation Ratios in Family Data." Ann. Ium. Genetics, "208 257-265.

Snyder, I. I.

1932 "Studies in Human Inheritance. IX. The Inheritance of Taste Deficiency in Man." Ohio J.Sci., 32: 436-440.

Stecher, P.G., ed.

1968 The Merck Index: An Encyclopedia of Chemistry and Drugs. Merck \& Co., Inc. Rahway, N.J.

Weinor, J.S. and J.A. Lourie

1969 Human Biology: A Guice to Field Methods. F. A. Davis Goupany, Fhiladeiphia. 